\title{
Recent progress in sodium alginate based sustainable hydrogels for environmental applications
}

\author{
Sourbh Thakur $^{\mathrm{a}, \mathrm{b}^{*}}$, Bhawna Sharma ${ }^{\mathrm{b}}$, Ankit Verma ${ }^{\mathrm{b}}$, Jyoti Chaudhary ${ }^{\mathrm{b}}$, Sigitas \\ Tamulevicius ${ }^{\mathrm{a}}$, Vijay Kumar Thakur ${ }^{\mathrm{c}}$. \\ ${ }^{a}$ Institute of Materials Science of Kaunas University of Technology, K. BarsauskoStr. 59, LT- \\ 51423 Kaunas, Lithuania \\ ${ }^{b}$ School of Chemistry, Shoolini University, Solan 173212, Himachal Pradesh, India \\ ${ }^{c}$ Enhanced Composites and StructuresCenter, School of Aerospace, Transport and \\ Manufacturing, Cranfield University, Bedfordshire MK43 OAL, UK
}

\begin{abstract}
Recently, there is a growing research interest in the applications and development of novel sustainable hydrogel materials in waste water treatment because of radically distinctive chemical and physical characteristics of hydrogels such as hydrophilicity, swell ability and modifiability to name a few. Hydrogels have exposed the hypernym functioning in the removal of a wide range of aqueous pollutants containing toxic dyes and heavy metal ions. A large amount of water gets incorporated in the three dimensional networks of hydrophilic structures of hydrogels. The prime objective of this review article is to render a presentation on the recent advances in the modifications of sodium alginate based hydrogels for the adsorptive removal of toxic pollutants. In addition, article also briefly gives the classification and properties of hydrogels and alginate.
\end{abstract}

Keywords: Alginate; sodium alginate based hydrogel; dye and metal removal; water purification. 


\begin{abstract}
*Corresponding authors Email: thakursourbh@gmail.com, sourbh.sourbh@ktu.lt, vijay.kumar@cranfield.ac.uk
\end{abstract}

\title{
1. Introduction
}

Recently, there has been a noticeable growth in the development of hydrogels composite and their applications in various fields including environmental remediation (Khan and Lo, 2016a; Li et al., 2013; Sahiner and Seven, 2014; Thakur et al., 2015, 2017b, 2017a). In regard to wastewater treatment, hydrogels based composites have exhibited superior performance in the adsorptive removal of different types of inorganic pollutants as well as organic pollutants (Mahdavinia et al., 2016; Ngah and Fatinathan, 2008; rights are reserved by Shivani and Shetye, n.d.). In many studies, hydrogels composites have clearly outcompeted the conventional adsorbents especially in terms of adsorption capacity (Burkert et al., 2007). Hydrogels are threedimensional, polymeric networks capable of absorbing large amount of water (Zhao et al., 2013). Hydrogels based composites have been tailored to grab most of the applications to get more functional features such as maximum equilibrium swelling, high rate of absorption, less residual content, porosity, uniformly soft, high durability, odorless, photo-stability (Ahmed, 2015; Gao et al., 2011). Hydrogels composites are chemically and physically stable, smooth, flexible polymeric network, reusable and multi-functional in nature. These flexible polymeric materials upholds the ability to swell and retain a consequential amount of water within their structure, but without being dissolved in water (Shetye et al., 2015). In the past 50 years, hydrogels have received appreciable attention from worldwide research community, due to their wide-ranging research interest moreover, many application holdings make this field more acceptable (Khan and Lo, 2016a). Research interest in the field of environmental science has been increasing with emphasis on use of bio-based hydrogels for advanced applications (Khan and Lo, 2016a). One of 
the major challenges is the recovery of hydrogel from solution after the completion of the adsorption or desorption process, especially in micro or nano-sized hydrogel (Izawa and Kadokawa, 2010). The selective removal and recovery of a targeted pollutants are the challenges because the co-present ingredients in wastewater often create unwanted competition and interference (F. Zhao et al., 2015). Furthermore, there have been some stability concerns for hydrogels composites which affect their fate and reusability (Roy et al., 2010).

It's been about many decades since research work is going on hydrogels and this field may come up with the dream of drought-free planet by purifying waste water (Fane et al., 2015). Although water purification by hydrogels is well set up by the various adsorption techniques but it quietly necessitates further improvements concerning degradability, intrinsic cellular interactions and strong mechanical properties in the different dynamic environment (Du et al., 2015). After acknowledging different research works of this field, we can define the ideal characteristics of hydrogels, along with the novel advancements in the material science (Vermonden et al., 2012a). Moreover, by overcoming the limitations of hydrogels in water treatment domain, we may build faith of society on water purification technologies because it promises the most practical and economic option for water purification from industrial and laboratory waste. In this article, we have made a platform for the upgraded hydrogel networks in relevance to the water treatment mission. In addition, template hydrogel materials stands up with many benefits in different fields like chemical catalysis, nano-engineering, nano-medicines, nano-energy and especially for reactions occurring in aqueous media (Figure 1) (Sahiner, 2013). The proven efficiencies of different chemical modifications has now been attracting the researchers to redesign and synthesize hydrogels with metal nano-particles in situ or ex situ (Lee and Mooney, 2001). Most of the work that has been done in one dimensional or two dimensional materials like surfactants 
or film, here is the applicable approach to generate three dimensional material with exterior and interior porous topography offers multifunctional utility. Recently, in situ approach of metal nano-particles with hydrogels is opening a new era on account of its fabulous properties such as optical, chemical, electronic and magnetic properties (Sahiner, 2013). Although many alternates may come out in future to solve the problem of aggregation of metal nano-particles and also their non-symmetrical behaviour in-between flexible hydrogel network. Despite the unique characteristics of these polymeric networks, science is yet not able to predict the quantitative mechanical response of the hydrogels based on their physico-chemical properties which limits our research ability to design something new (Wang et al., 2017). This review article focuses on the recent developments in sodium alginate based hydrogels and composites for water purification. The classification of hydrogels, synthesis of hydrogels and composites along with the properties of alginate have been discussed in this article.

\section{Method}

Potential adsorption from bio-renewable resources involves development of the most commercial polymers based products for environmental application. The bio-based polymeric hydrogels have proved their efficiencies many times and also have added an advantage of bio-degradation in an aqueous media. Among numerous hydrogels, sodium alginate based hydrogels have allured the research interest for number of applications due to their inbuilt physico-chemical nature. But this research field is still in an early stage of development with bounded information regarding literature of sodium alginate based hydrogels for water remediation. In this article, the data collection involved several steps, started from the classification, preparation, utilization and reusability of hydrogels to the recent advancements in sodium alginate loaded hydrogels for the removal of organic and inorganic pollutants. The development of "Sodium Alginate based 
Hydrogels" initiatives, require inclusive knowledge on alginate based materials and different sustainable materials for new tailored properties and applications. The synthesis and applications of novel innovative materials from alginate will improve the horizon of sustainable hydrogels as well as possibly address the problem of lack of human friendly/biocompatible tissues and scaffolds materials. Therefore, we summarize various efforts of researchers all around the globe to develop new sustainable hydrogel materials for environmental applications from alginate based polymers in the present manuscript. This perspective article in tends to show that developed hydrogels from bio-renewable resources can be efficiently prepared and executed as potential environmental friendly, biodegradable and economic materials. This reviews some important questions about the potential use of "Sustainable Biomaterials" in advanced applications including environmental engineering.

\section{Classification of Hydrogels}

Hydrogel products can be classified on several bases (Ahmed, 2015):

\subsection{Based onSource}

Source means a thing or person from which something is obtained. So, on the basis of source, these polymeric materials can be classified into two categories: synthetic or natural source (Nayak et al., 2010). The natural polymeric materials show profitable bio-compatibility, biodegradability but these are far behind in case of mechanical properties. However, on the other hand, there is a lack of bio-active properties in synthetic polymeric material.

\subsection{According to Polymeric Composition}

Composition simply means "act of combining of elements to form a whole". On the basis of this, hydrogel products have been categorized into the following: (a) hydrogels belong to the polymer network consisting of basic structural monomer unit formed via homo-polymerization (Qiu and 
Park, 2001). Homo-polymer hydrogels are those polymer systems which emerge from single unit of monomers and comprises of normal auxiliary segment of any polymer framework. There might be some possibility of having cross-linked skeletal structures, which depends upon the polymerization technique as well as nature of the monomer being used; (b) co-polymeric hydrogels are the chemical compounds of high molecular weight made up of two or more different monomer subunits with not less than one hydrophilic component organized in a random, block or alternating configuration across the chain of the polymer network (Thakur, 2016); (c) multi-polymer interpenetrating polymeric hydrogels, the salient class of hydrogels that consist of two different cross-linked components of synthetic or natural polymer, arranged in a network form (Shetye et al., 2015). This class is further split up into semi-interpenetrating polymeric hydrogel in which one of the hydrogel component is non-cross-linked another is cross-linked polymer or monomer.

\subsection{Based on Configuration}

These are generally based on the physical arrangement and reactant (chemical) composition of the hydrogel and can be classified as: (a) amorphous (no apparent organization), (b) semicrystalline (imperfectly crystalline) (Thoniyot et al., 2015a); it is a mixture of distinct as well as indistinct (amorphous) phases, (c) crystalline (regular arrangement of atoms in space lattice), (d) hydrogen bonded hydrogels.

\subsection{Based on Type of Cross-linking}

This class has two different division of cross-linked network of hydrogels based on their chemical /physical nature (Caló and Khutoryanskiy, 2015). Physical networks have been found to exhibit temporary junctions that appear from physical relations like ionic interactions, hydrogen bonds, or hydrophobic interactions (L. Z. Zhao et al., 2015) whereas, chemically cross- 
linked networks have unchanging junctions. This is generally achieved by using physical activities like coalition, conglomeration, connection, crystallization, difficulty and hydrogen bonding. Conversely, a chemical procedure is a process in which incorporated bivalent crosslinking is idolized to assemble a synthetic hydrogel. Physical hydrogels are convertible/reversible in nature due to the in-formational augmentations, while synthetic hydrogels are unchangeable/long lasting in nature. Cross-linking makes the network viscoelastic which provides hardness and stickiness to the structure.

\subsection{Based on Physical Appearance}

The outward composition of hydrogel film or microsphere depends on the technique of polymerization, cross-linking or any other preparation process.

\subsection{Classification According to Network Electrical Charge}

This classification is divided into four main types based on the presence/absence of electrical charge pointed on the double cross-linked chains (Ahmed, 2015): (a) neutral (non-ionic) gels; (b) ionic gels (including anionic or cationic); (c) amphoteric electrolyte (containing both acidic as well as basic groups); (d) zwitter-ionic (having anionic and cationic groups together in each structural repeating unit).

\section{Preparation of Hydrogels}

Hydrogels are commonly defined as semi-solid, three-dimensional, polymeric networks obtained from a class of synthetic or natural polymers (collagen, gelatin, starch, alginate etc.) which can retain significant amount of water and biological fluids (Shi et al., 2011). During the hydration process, the structure of polymeric network is created by the domains or hydrophilic groups (Talaat et al., 2008). Preparation of hydrogels is based on hydrophilic monomers (polar part first to be hydrated) and hydrophobic monomers (forms hydrophobically-bounded water) are 
sometimes used to control the properties for specific applications (Can et al., 2007), (Thoniyot et al., 2015a). Traditionally, chemical polymerization techniques are used in case of synthetic polymers that form hydrogels. The mechanical strength of the synthetic polymers has been reported to cause slow degradation rate, but on the other hand, it provides the durability as well (Mehrali et al., 2017). Hydrogels are mainly synthesized using polar monomers and their preparation starts from initiation reaction and ends up at termination. In addition, three fundamental parts (Figure 2) of the hydrogels preparation are monomer, cross-linker and initiator (Ahmed, 2015). For example, Thakur et al., prepared sodium alginate based hydrogels by a polymerization technique employing acrylic acid as monomer, N, $\mathrm{N}^{\prime}$ methylenebisacrylamide and potassium persulphate as cross-linker and initiator respectively (Thakur and Arotiba, n.d.). Diluents like water and biological fluids can be used to control the final hydrogel properties and the heat of polymerization (Ma et al., 2010). Starting materials can be optional and is divided into synthetic polymers, natural polymers or combination of both. A number of polymerization methods can be adopted to form hydrogels: (a) Bulk polymerization means two or more monomers are combined with the help of suitable initiator for the formation of hydrogel. In this polymerization, monomers make homogeneous composition of hydrogels. (b) Solution polymerization/cross-linking means ionic and neutral monomers are reacted together with suitable cross-linking agent. The reaction is initiated with the help of UVirradiation or using a redox initiator system. (c) Suspension polymerization or inverse-suspension polymerization means monomers as well as initiator are diffused as a homogenous mixture in the hydrocarbon phase. (d) Polymerization by irradiation means high energy radiations such as like electron beams/gamma rays etc are employed as an initiator to prepare the hydrogel (Karadağ et 
al., 2001) and (e) grafting to a support means for increases the mechanical properties of the hydrogel, hydrogels are coated with the strong grafting agents.

\section{Preparation of Hydrogels Composite}

Hydrogels composite have been advanced by adding a wide range of nano-materials (metallic, polymeric, carbon-based) (Merino et al., 2015; Shin et al., 2011; Zuo et al., 2015). Nanomaterials can be incorporated within the bulk hydrogel framework. Five basic methods have been used to obtain a uniform distribution (Thoniyot et al., 2015a): (a) preparation of hydrogel in a nano-particle suspension, (b) addition of the nano-particles into hydrogel matrix after gelation, (c) reactive nano-particle preparation within a preformed hydrogel, (d) hydrogels nanocomposite via cross-linking and (e) development of hydrogel nano-composite using polymers, metallic nano-particles and different gelator molecules (Khan and Lo, 2016a).

\subsection{Preparation of Hydrogel in Nano-particle Suspension}

The perfect technique to build hydrogel composites is the gelation of nano-particles suspension in hydrogel matrix. Through this technique, hydrogel composites becomes optically and mechanically responsive (Omidian et al., 2006). In this technique, monomers, cross-linkers and nano-particles are combined to form hydrogel composites through gelation (Thakur et al., 2016). This technique is the easiest technique for the synthesis of hydrogel composites. Sershen et al., synthesized optomechanically $\mathrm{N}$-isopropyl acrylamide/acrylamide hydrogel matrix by adding gold nano-particles through gelation using initiator ammonium persulfate and accelerator tetramethylethylenediamine (Sershen et al., 2002). The hydrogel applications in the mechanical field can be enhanced by adding the nano-particles into the hydrogel matrix.

\subsection{Addition of Nano-particles into Hydrogel Matrix after Gelation}


In this method, nano-particles are added in the hydrogel matrix after the gelation process. Yissar et al., added gold nano-particles into polymer hydrogel matrix after the electro polymerization (Pardo-Yissar et al., 2001). Electro polymerization cannot be achieved in the presence of the gold nano-particles because of aggregation of gold nano-particles in electric field (Kim and Randall Lee, 2006). In this work, cross-linked polyacrylamide gels were prepared on gold-wire electrodes by the electro-polymerization of acrylamide along with $\mathrm{ZnCl}_{2}$ and $\mathrm{N}, \mathrm{N}$ ' methylenebisacrylamide.

\subsection{Reactive Nano-particle Preparation within Preformed Hydrogel}

Langer's group formulated this technique, which consists of precursors loading into a hydrogel matrix, rather than formed nano-particles (Wang et al., 2004). For example, hydrogel network containing embedded Au (III) ions with thiol groups was produced. Hydrogel matrix containing thiol group was able to modulate gold nano-particles formation on the addition of a reducing agent. This prompted the arrangement of hydrogel composites with un-collected nano-particles (Thoniyot et al., 2015a; Wu et al., 2013). A modified technique of nano-particle synthesis within hydrogel matrix in the absence of thiol group was developed by Saravanan et al., (Saravanan et al., 2007). Ag nano-particle/polyacrylamide composite was synthesised by free-radical crosslinking polymerization using acrylamide and Ag (II) ions aqueous solution. Comparison between the non-Ag-loaded polyacrylamide gel and Ag-loaded polyacrylamide nano-composite hydrogels showed remarkable enhancement in the properties of swelling along with the electron transfer resistance. These properties were found to depend on the amount of Ag nano-particles in the hydrogel.

\subsection{Hydrogel nano-composites via Cross-linking}


Hydrogel composites can be synthesized by using semiconductor nano-particle as a cross-linker. Zhang et al., prepared semiconductor hydrogel nano-composites by self-polymerization in the presence of light (Zhang et al., 2013). In this technique, mainly four parts were used: (a) $\mathrm{H}_{2} \mathrm{O}$, (b) semiconductor nano-particles of zinc oxide, titanium dioxide, $\mathrm{Fe}_{2} \mathrm{O}_{3}$, tin dioxide, cadmium selenide or cadmium telluride, all nano-particles were water soluble, (c) N, N-dimethyl acrylamide and (d) clay nano-sheets. Semiconductor nano-particles were used to initiate the selfpolymerization of N, N-dimethyl acrylamide (Paddon et al., 2013). Authors mentioned that cadmium selenide and cadmium telluride were capable to synthesize strong hydrogel even in the presence of visible light. They also recommended that valuable nano-particles can be immobilized in hydrogels for their aggregate application in the sake of joining their mechanical and physiochemical properties. Additionally, the declared result for this hydrogel demonstrated superb mechanical quality (most noteworthy compressive nature of 4.153 MPa and inflexibility $1.535 \mathrm{MPa}$ ) and high adaptability (most extraordinary protracting of $2784 \%$ ).

\subsection{Hydrogel Composites Formation using Nano-particles, Polymers and Distinct Gelator}

\section{Molecules}

Wu et al., 2013 prepared silicon based anodes by adding silicon nano-particles into a conducting polymer hydrogel (Wu et al., 2013). A well-developed three-dimensional structure of conducting polymer hydrogel with silicon nano-particles was produced through in situ polymerization. The following interactions were described in the synthesis of this hydrogel: (a) hydrogen bonding between silicon surface and phytic acid, (b) electrostatic interaction among silicon surface and positively charged aniline polymer. The viscous hydrogel mixture became dark green because of phytic acid gelator (C. Wang et al., 2013). Such a hierarchical hydrogel system merges with different important characteristics including persistent electrically conductive polyaniline 
network, binding with the Si surface through either the cross-linker hydrogen bonding with phytic acid or electrostatic interaction with the positively charged polymer and porous space for volume development of Si particles. The developed materials demonstrated cycle life of 5,000 cycles with more than $90 \%$ limits maintenance at current thickness of $6.0 \mathrm{~A} \mathrm{~g}^{-1}$.

\section{Biodegradability of Hydrogels}

To nullify the environmental effects of solid wastes, bio-degradable polymers are now emerging as an alternate for non-biodegradable polymeric materials (Li et al., 2012). For the fabrication of any bio-degradable material such as bio-plastics, the material is designed to develop some changes in its chemical behaviour under fixed environmental conditions (Kaith et al., 2015). Biodegradability is one of the environment-friendly responses of the hydrogels that ensures its utility in target drug delivery applications as hydrogels degraded by simple aqueous breakdown are extensively used for drug distribution. However, the hydrogels degraded by enzymes are regarded as site specific transporting carriage materials. This is due to the fact that enzymes lie over the restricted sites of the body (Bouhadir et al., 2001). Usually, hydrogels are degraded by different types of methods (Figure 3) for example, a novel approach was developed by Kaith et al., using composting method and soil burial to degrade hydrogels within 77 days of contact (Kaith et al., 2015). In another work, Jeon et al., developed bio-degradable alginate based photo cross-linked hydrogels for tissue engineering application. They have designed the material with the ester linkages which was hydrolytically degradable during photo polymerization reaction (Jeon et al., 2009). Similarly, bio-degradable oligopeptide cross-linked polymethacrylic acid based hydrogel was developed by Knipe et al., which was used to deliver protein in small intestine. The enzymatic degradation was catalyzed by the trypsin enzymes present inside the small intestine (Knipe et al., 2015). In conclusion, because of better bio-degradability of 
hydrogels, they can be considered as the pioneer material for fulling various targets of the medical line.

\section{Reusability of Hydrogels}

From the economic point of view, hydrogels are most appropriate as their adsorption limit doesn't reduce after a couple of recoveries and reuses (Pakdel and Peighambardoust, 2018). In hydrogels, high adsorption limit, fast adsorption rate, high mechanical quality, biodegradability, broad $\mathrm{pH}$ values and reusability are sensible for significant metals and dye removal. (Pakdel and Peighambardoust, 2018). The ordinary reusability of the hydrogel has also been shown demonstrated by rehashing the adsorption-desorption procedure (Vivek and Prasad, 2015), while keeping up an adequate execution (Chiew et al., 2016). Hydrogel has been found to show an incredible degree of extraordinary characteristics for reusability. Upto five adsorptiondesorption cycle hydrogel were found to give good results (Yi et al., 2018). Reusability of adsorbent is one of the fundamental parameter in the functional applications of wastewater treatment (Awual et al., 2015, 2014). Yi et al. examined the reusability of sodium alginate/polyvinyl alcohol/graphene oxide hydrogel with five cycle's tests (Yi et al., 2018). It was concluded from the detailed analysis that the adsorptive property for $\mathrm{Cu}(\mathrm{II})$ and $\mathrm{UO}_{2}$ (II) was diminished after the main sorption-desorption cycle and afterward without tremendous assortment until the fifth cycle, showing that sodium alginate/polyvinyl alcohol/graphene oxide microspheres can be reused in numerous cycles without basic adversity in its adsorption characteristics (Yi et al., 2018). Recovery and reusability of the hydrogel were considered utilizing methyl orange as adsorbate by Balachandran and Edamana in 2015 (Vivek and Prasad, 2015). The approximate time period of 20 minute was reported for desorption process and $97 \%$ of the colour was recovered. The execution of the hydrogel for five cycles was incredible (90-98 
$\%)$. Chiew et al. have explored the mechanical stability of calcium alginate and alginatehalloysite nano-composite beads for the removal of $\mathrm{Pb}(\mathrm{II})$ ions. Reusability was summarized up to ten successive cycles and percentage desorption was continued to exist at $94 \%$ for both type of composite beads (Chiew et al., 2016).

\section{Utilization of Hydrogel Products}

Hydrogels have been utilized in the field of target drug delivery applications due to their distinctive physical properties. The sponge like porous network of hydrogels makes them compatible for filling multiple types of drugs inside their three dimensional matrix (Vermonden et al., 2012b). The percentage drug release is managed by the diffusion coefficient of the micro and macromolecules. Hydrogels have been leading as candidate material for tissue engineering because of their uncommon structural resemblances with the extracellular matrix (Kim et al., 2015; Yang et al., 2014). Based on the innovative research worldwide, new opportunities are coming to conquer the challenges of this field due to their capability to command the surface morphology and shapes during cell transplantation. It has attended numerous examinations focused on explorations transporting carriage material for bio-active substances or as a platform for organizing the cells and to certain the growth of targeted tissues (Kamata et al., 2015; Seliktar, 2012). In addition to all leading properties of hydrogels, it can also be changed into defined geometries and purpose of this is to control cell shape and to bring specified biomimetic design. The physico-chemical properties of the hydrogels can be changed in accordance to the specified natural cells or tissue by controlling its cross-linking and polymer chemistry in order to bring out required biological results (Rosales and Anseth, 2016; Uto et al., 2017). The success of stem cell culture exclusively depends upon targeted differentiation and it is believed that homogenous hydrogel surfaces are convenient for the differentiation of stem cells (Higuchi et al., 
2013). Flexible and soft conductors are valuable parts of bioelectronics that are useful in biomedical applications. Conductive hydrogels can be effectively used as soft conductors because of their molecular resemblance to soft tissues and high water absorption ability. Recently, hydrogels have been utilized in supercapacitors, energy storage, human health monitoring and electronic skin to name a few (Han et al., 2017; Oh et al., 2016). The adsorption mechanism of hydrogels is now emerging as feasible option to acquire sustainable approach towards water treatment mission. The reusability of hydrogels has been revealed by regaining the adsorption capacity by many consecutive cycles (Khan and Lo, 2016b; Liu et al., 2017) and this property makes it as economical material for challenging rest of the developing techniques.

\section{Alginate (Natural Polysaccharide)}

Alginate comprises of $30-60 \%$ of brown algae. In account of its chemical and physical properties, it has been extensively studied due to its ability to form gels and micro-particles (Goh et al., 2012; Khotimchenko et al., 2001; Lee and Mooney, 2012; Pawar and Edgar, 2012; Pereira et al., 2013; Thakur, 2016, 20016). For example, Pereira et al prepared alginate based film for bio-medical applications. The alginate based hydrogel thin film composed of alginate and aloe vera gel was used for the treatment of skin. Alginate mixtures are considered to be biocompatible, safe, perishable and non-immunogenic (Paques et al., 2014). It can be marked as anionic biopolymer consisting of mannuronic and guluronic acid units in the irregular blocks (You et al., 2001). The mannuronic acid forms $\beta(1 \rightarrow 4)$ linkages and guluronic acid forms $\alpha$ $(1 \rightarrow 4)$ linkages. The mannuronic and guluronic acid units are joined by glycosidic linkages. Guluronic acid segments exhibit rigid and bended conformations that provides stiffness to the molecular chains (de Vos et al., 2006).

\subsection{Alginate Hydrogels}


Alginate hydrogels can be designed via cross-linking the polymer chains. The physical and chemical properties of the alginate hydrogels are dependent on cross-linking density, type of cross-linking along with the molecular weight (Franklin and Ohman, 2002). For example, Chan et al., synthesized alginate cross linked network based on external and internal gelation method. The prepared sample was utilized for coating and drug delivery of living system (Chan et al., 2006). One of the suitable method for the formation of alginate hydrogels is inter-molecular cross-linking in which only guluronic groups of alginate participate with divalent cation such as calcium (El-Sherbiny, 2010). Numerous divalent cations show distinctive affinity towards alginate but calcium is more often used for alginate gelation. The properties of alginate hydrogels such as solubility, hydrophobicity and biological activity can be improved by modifying alginate through their available hydroxyl and carboxyl groups (Zimmermann et al., 1992).

\subsection{Alginate Modification}

Molecular adaptations generally depends on three imperative factors namely reactivity, solubility and characterization (Pawar and Edgar, 2012a) as shown in Figure 4.

\subsubsection{Solubility}

The dissolvability of alginates in water is represented by three parameters: (a) $\mathrm{pH}$ of the dissolvable, (b) ionic quality of the medium and (c) nearness of gelling particles in the dissolvable. The solvency of alginates depends emphatically on the condition of the spine carboxylic acid groups. For derivatization, alginate mixtures can be dissolved in natural aqueous and organic or combined aqueous-organic media. The possibility of solvent system can impose the variety of reagents which can be used for modification (Galant et al., 2006).

\subsubsection{Reactivity}


The two secondary -OH positions (C-2 and C-3) or the one carboxylic group at C-6 position can be modified in alginate mixtures. The reactivity difference between these two functionalities can be useful for selective modifications (Donati et al., 2003). Because of little reactivity differences, selection for the modification is challenging for both positions. The reaction can be controlled in terms of selective modification of the mannuronic and guluronic block residues. The action of alginates towards acids, bases and diminishing agents cannot be ignored when performing derivatization responses. Aggressive degradation responses can cause quick sub-atomic weight reduction in short periods (Yang et al., 2011).

\subsubsection{Characterization}

In order to realize the chemical substitution configurations in the alginate derivatives, there is always a need of various alginate samples within a range of mannuronic/guluronic value. For the detailed understanding of the substitution patterns, (Kim et al., 2000) derivatization of alginate mixture is required in mannuronic and guluronic blocks. More facilitated analytical techniques are often required to study the complex nature of the alginate co-polysaccharide backbone. Because of the unpredictable nature of the alginate co-polysaccharide backbone, utilization of cutting edge investigative methods is most vital.

\section{Sodium Alginate}

Sodium alginate is a product of many unprocessed sugars. It has the capability to be dissolved in both cold and hot water with strong stirring. In presence of divalent calcium ion, sodium alginate builds a gel without any need of heat. In modern food technology, sodium alginate is used to create spheres in which sodium alginate is blended with calcium salts (Eghbalifam et al., 2015). In food industry, sodium alginate is used to increase viscous nature of liquids, as an emulsifier (Mahdavinia et al., 2016) as well as making tasteless indigestion tablets (Park and Kim, 2001). 


\section{Sodium Alginate based Hydrogels for Water Purification}

Sodium alginate based hydrogels have been used in wastewater treatment (Belhouchat et al., 2017; Bhattacharyya and Ray, 2015; Fan et al., 2013; Fatin-Rouge et al., 2006; Gao et al., 2011; Hosseinzadeh and Abdi, 2017; Karthiga Devi et al., 2016; Lakouraj et al., 2014; Lam et al., 2017; Lu et al., 2015; Mahdavinia et al., 2013; Ngah and Fatinathan, 2008; Rashidzadeh et al., 2015; Ren et al., 2016; Tally and Atassi, 2016; Thakur, 2016; Thakur et al., 2016; Thakur and Arotiba, 2017, n.d.; W. Wang et al., 2013b, 2013a; Wu et al., 2017; Zhuang et al., 2016) (Table 1), (Table 2). Mahdavinia et al., prepared kappa-carrageenan-sodium alginate/montmorillonite (CarAlg/MMt) hydrogel nano-composite by using acrylamide as monomer (Mahdavinia et al., 2013). The synthesized hydrogel nano-composite was utilized for the adsorption of cationic crystal violet dye from water. The maximum adsorption capacity obtained was found to be 88.8 $\mathrm{mg} \mathrm{g}^{-1}$. The basic Na-montmorillonite (Na-MMt) clay and hydrogel nano-composite containing $0.25 \mathrm{~g}$ and $0.5 \mathrm{~g}$ of basic Na-MMt (CarAlg/MMt0.25, CarAlg/MMt0.5) were characterized by XRD. A sharp diffraction peak at $2 \theta=7.6^{\circ}$ with d-spacing of $11.61 \AA$ confirmed the basic NaMMt. The peak at $2 \theta=7.6^{\circ}$ vanished due to the intercalation of Na-MMt clay in the matrix of nano-composite. In the TEM image of CarAlg/MMt0.25, the black and fine lines correspond to Na-MMt layers. The surface of hydrogel without clay (CarAlg) was found to be smooth and tight. The surface became porous after the addition of Na-MMt nanoclay into the hydrogel. The adsorption kinetics was used to measure the expected equilibrium time for adsorption of crystal violet dye (Mahdavinia et al., 2013). The adsorption of crystal violet dye was sharply increased at the beginning and then became constant. The equilibrium time of 2 hours was reported for dye adsorption. The dye adsorption capacity was increased by adding Na-MMt clay in hydrogel. The rate of adsorption of dye was increased with the amount of clay in hydrogel. The formation of 
active centers because of porosity was the cause of increase in speed of crystal violet adsorption by the hydrogel nano-composite (Wang et al., 2008). The maximum adsorption capacity of 88.8 $\mathrm{mg} \mathrm{g}^{-1}$ was achieved by the CarAlg/MMt0.5 sample.

Sodium alginate-g-poly(acrylic acid-co-acryl amide)/clinoptilolite hydrogel nano-composite was synthesized through free radical polymerization technique (Rashidzadeh et al., 2015). The developed hydrogel nano-composite was utilized for the removal of methylene blue dye and $94.34 \mathrm{mg} \mathrm{g}^{-1}$ was the maximum adsorption capacity. FTIR spectrum of sodium alginate-gpoly(acrylic acid-co-acryl amide)/clinoptilolite, sodium alginate-g-poly(acrylic acid-co-acryl amide) and methylene blue adsorbed sodium alginate-g-poly(acrylic acid-co-acryl amide)/clinoptilolite are given in Figure 5a-c. In Figure 5a and 5b, the absorption bands at 1650 $\mathrm{cm}^{-1}$ and $1450 \mathrm{~cm}^{-1}$ were due to sodium alginate and carboxylate stretching respectively. Broad band at $3000-3500 \mathrm{~cm}^{-1}$ was due to the stretching of hydroxyl groups of the polysaccharide. The shift in the $-\mathrm{COOH},-\mathrm{OH}$ adsorption band in the spectrum of methylene blue adsorbed sodium alginate-g-poly(acrylic acid-co-acryl amide)/clinoptilolite (Figure 5c) indicated the adsorption of methylene blue dye onto sodium alginate-g-poly(acrylic acid-co-acryl amide)/clinoptilolite hydrogel nano-composite. The sodium alginate-g-poly(acrylic acid-co-acryl amide)/clinoptilolite hydrogel nano-composite was composed of pores with size of ten microns as indicated in SEM morphology (Figure 5d). Adsorption mechanism was explained on the basis of change in colour of sodium alginate-g-poly(acrylic acid-co-acryl amide) hydrogel (Figure 6a,c) and sodium alginate-g-poly(acrylic acid-co-acryl amide)/clinoptilolite hydrogel nano-composite (Figure 6b,d) after the adsorption of methylene blue dye. The electrostatic attraction between amide and carboxylic of sodium alginate-g-poly(acrylic acid-co-acryl amide)/clinoptilolite hydrogel nanocomposite and imine groups of methylene blue dye was responsible for adsorption of dye. 

adsorbent for the adsorption of methylene blue dye (Wu et al., 2017). The graphene oxide used for the synthesis of hydrogel nano-composite was produced by an improved Hummers method. The highest adsorption capacity of synthesized absorbent was $133.24 \mathrm{mg} \mathrm{g}^{-1}$. The thickness of 1 to $2 \mathrm{~nm}$ and micro meter-sized planes of graphene oxide was confirmed by atomic force microscopy analysis (Figure 7a). TEM image of graphene oxide with broken surface is shown in Figure 7f. The colour of sodium alginate/ $\beta$-cyclodextrin/graphene oxide hydrogel nanocomposite was faint yellow whereas colour of methylene blue loaded sodium alginate/ $\beta$ cyclodextrin/graphene oxide hydrogel nano-composite was dark blue black (Figure 7b). The faint yellow colour of sodium alginate/ $\beta$-cyclodextrin/graphene oxide hydrogel nano-composite was due to the presence of graphene oxide. The porous and honeycomb-like structure of sodium alginate/ $\beta$-cyclodextrin/graphene oxide adsorbent was confirmed by SEM morphology (Figure 7c-e). The adsorption of methylene blue onto sodium alginate/ $\beta$-cyclodextrin/graphene oxide hydrogel nano-composite was explained via hydrogen bonding, $\pi-\pi$ interaction and electrostatic attraction (Heidarizad and Şengör, 2016) as represented in Figure 8.

Thakur et al., prepared titania incorporated sodium alginate/acrylic acid hydrogel nanocomposite for the adsorption of methylene blue dye from aqueous solution (Thakur et al., 2016). The reported maximum adsorption capacity was $2257.36 \mathrm{mg} \mathrm{g}^{-1}$. The synthesis of hydrogel nano-composite was explained by free radical polymerization of acrylic acid onto sodium alginate using potassium persulphate and $\mathrm{N}, \mathrm{N}^{\prime}$-methylenebisacrylamide as initiator and crosslinker respectively. The adsorption mechanism of methylene blue dye was explained by electrostatic attraction (between $\mathrm{TiO}_{2}$ or $\mathrm{COO}-$ and cationic dye) and hydrogen bonding (between OH and imines groups of dye) (Pourjavadi et al., 2014) (Figure 9). 

synthesized for the adsorption of cationic as well as anionic dyes (Fan et al., 2013). The developed ternary hydrogel nano-composite was ionically cross-linked by using $\mathrm{Ca}$ (II) ion. On applying stress, the pure polyacrylamide hydrogel was destroyed (Figure 10a-c). However, graphene oxide/sodium alginate/polyacrylamide hydrogel nano-composite was not destroyed on applying stress (Figure 10d-f). On the removal of stress, graphene oxide/sodiumalginate/polyacrylamide hydrogel nano-composite regained its original shape. The possible scheme for graphene oxide/sodium alginate/polyacrylamide ternary hydrogel nanocomposite is shown in Figure 10g. Intercalation of layered structure graphene oxide with hydrogel network was presented. The mechanical stability of hydrogel nano-composite was improved by the exchange of load among graphene oxide nanosheets and polymer chains. Ionically cross-linked as well as covalently cross-linked polymers were presented in hydrogel network. Also, polymer chains of hydrogel interacted with graphene oxide nanosheets through hydrogen bonding. The sponge-like morphology was reported for hydrogel samples as shown in Figure 11. The structure of polyacrylamide and sodium alginate/polyacrylamide hydrogels contained holes with uniform size (Figure 11a-c). The lamellar and dense structures were formed after the addition of graphene oxide into the hydrogel network (Figure 11d-f). The change in colour of different dyes after the adsorption by sodium alginate/polyacrylamide hydrogel nano-composite is represented in Figure 12. The following interactions were used to explain the adsorption mechanism: (a) amino and azo functional group of dye with carboxylic functional groups of hydrogel nano-composite, (b) $\pi-\pi$ interactions between aromatic groups.

Sodium alginate based silver hydrogel nano-composite was developed by one step green method (Karthiga Devi et al., 2016). Devi et al., have used this hydrogel nano-composite for methylene 
blue dye removal and $213.7 \mathrm{mg} \mathrm{g}^{-1}$ was the maximum adsorption capacity reported. Synthesis of silver nano-particles was performed by reduction with M. maderaspatna extract. Silver nanoparticles were characterized by using UV-vis-spectrophotometric analysis. The band at $443 \mathrm{~nm}$ confirmed the formation of silver nano-particles (A Bhosale and M Bhanage, 2015). Hydrogel beads were synthesized by gelation process of sodium alginate and carbopol 937. Finally, silver nano-particles introduced into the hydrogel beads led to the formation of silver nano-composite for dye adsorption studies. The crystalline structure and size of silver nano-composite was

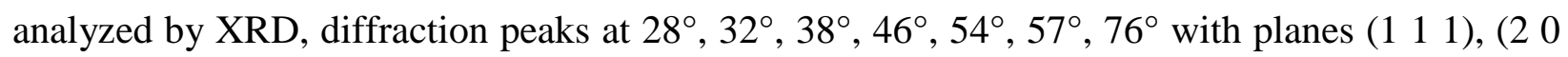
0), (2 10 0), (2 2 0), (3 11 1), (2 2 2 2), (4 20 ) corresponded to crystalline silver nano-particles. TEM analysis was used to verify the size and shape of the silver nano-particles containing carbopolalginate hydrogel beads. The reported average crystal size was about $19.3 \mathrm{~nm}$ with uniform shape.

The emulsion micelle has been incorporated into the vinyl-functionalized sodium alginate-comethyl acrylic acid-co-italic acid hydrogel for the formation of nano-porous hydrogel (W. Wang et al., 2013b). This synthesized nano-porous hydrogel was used for the removal of $\mathrm{Pb}(\mathrm{II})$ ion from aqueous solution. Three dimensional network of vinyl-functionalized sodium alginate-comethyl acrylic acid-co-italic acid hydrogel was developed through free radical polymerization reaction (Figure 13). The reaction between sodium alginate and glycidyl methacrylate led to the introduction of vinyl groups on sodium alginate. The sulfate anion radicals were produced by hemolytic breakage of ammonium persulfate (Buchholz and Graham, 1998). The chain propagation step was carried out in between radicals, vinyl-functionalized sodium alginate chain and monomers. Different chains of sodium alginate were cross-linked through methyl acrylic acid and italic acid polymer chains. Emulsion micelles were formed by sodium dodecyl sulfonate 
and n-Octane, which were introduced into the cross-linked hydrogel network. Nano porous hydrogel was formed after the removal of emulsion micelles as shown in Figure 13. The peaks at $\delta 3.55-4.01$ and $\delta 4.86$ were due to the non-anomeric and anomeric protons in the ${ }^{1} \mathrm{H}$ NMR spectrum of sodium alginate (Figure 14a). New peaks were represented in the vinylfunctionalized sodium alginates hydrogel due to presence of methyl protons and methacryloyl double bonded hydrogen's at $\delta 1.80 \mathrm{ppm}$ and $\delta 5.60, \delta 6.02 \mathrm{ppm}$, respectively. In ${ }^{13} \mathrm{C}$ NMR spectrum of sodium alginate, peaks in the range of $\delta 63.5-102.18 \mathrm{ppm}$ were due to the sugar carbons of sodium alginate (Figure 14b). The following new peaks were observed in the ${ }^{13} \mathrm{C}$ NMR spectrum of vinyl-functionalized sodium alginate: (a) $\delta 19.46 \mathrm{ppm}$ due to methyl carbon, (b) $\delta 129.28$ and $\delta 138.31 \mathrm{ppm}$ assigned to vinyl carbons, (c) $\delta 171.86 \mathrm{ppm}$ due to carbonyl carbon. Hence, modification of sodium alginate with glycidyl methacrylate and incorporation of vinyl groups on the sodium alginate matrix were confirmed by these NMR results. The ${ }^{1} \mathrm{H}$ NMR and ${ }^{13} \mathrm{C}$ NMR spectrum of vinyl-functionalized sodium alginatewas identical to modified cashew gum with glycidyl methacrylate, indicating mechanism of modification for sodium alginate and cashew gum with glycidyl methacrylate was identical (Guilherme et al., 2005). Ring opening mechanism was believed to take place between sodium alginate with glycidyl methacrylate ${ }^{91}$. The smooth and dense surface without any pore was observed in the morphology of vinylfunctionalized sodium alginate-co-methyl acrylic acid-co-italic acid hydrogel (Figure 15a). However, structure with uniform pores $(20-60 \mathrm{~nm})$ was obtained after the addition of emulsion micelle into the vinyl-functionalized sodium alginate-co-methyl acrylic acid-co-italic acid (Figure 15b-d).

Sodium alginate-g-polyacrylic acid/polyvinylpyrrolidone/gelatin granular hydrogel was synthesized through grafting and cross-linking using gelatin, acrylic acid and 
polyvinylpyrrolidone (W. Wang et al., 2013a). The developed sodium alginate-g-polyacrylic acid/polyvinylpyrrolidone/gelatin granular hydrogel was utilized for the adsorption of heavy metal ions. The adsorption capacity for $\mathrm{Ni}(\mathrm{II}), \mathrm{Cu}(\mathrm{II}), \mathrm{Zn}(\mathrm{II})$ and $\mathrm{Cd}(\mathrm{II})$ was found to be 3.028 mmol g $\mathrm{g}^{-1}, 3.146 \mathrm{mmol} \mathrm{g}^{-1}, 2.911 \mathrm{mmol} \mathrm{g}^{-1}$ and $2.862 \mathrm{mmol} \mathrm{g}^{-1}$ respectively. The sodium alginate-g-polyacrylic acid/polyvinylpyrrolidone/gelatin granular hydrogel was prepared by chemical and physical reactions (Pourjavadi et al., 2008) (Figure 16). The $\mathrm{H}^{+}$of acrylic acid was used to generate electro positivity on polyvinylpyrrolidone and gelatin. Hence, polyvinylpyrrolidone and gelatin were interacted with sodium alginate and grafted polyacrylic chains through electrostatic and hydrogen-bonding. These interactions among polyvinylpyrrolidone, gelatin, sodium alginate and acrylic acid led to formation of granular hydrogel. Figure 17a shows the gel like photograph of sodium alginate-g-polyacrylic acid hydrogel. After the addition of polyvinylpyrrolidone and gelatin, shape of sodium alginate-gpolyacrylic acid hydrogel was converted into the granular (Figure 17b). This granular shape of hydrogel was maintained in the dry state (Figure 17c). Sodium alginate-g-polyacrylic acid hydrogel exhibited smooth surface (Figure 17d), whereas sodium alginate-g-polyacrylic acid/polyvinylpyrrolidone/gelatin granular hydrogel displayed rough and porous surface (Figure 17e). Adsorption capacity and recovery capability of the sodium alginate-g-polyacrylic acid/polyvinylpyrrolidone/gelatin granular hydrogel for various metal ions were investigated. The adsorption capacity of sodium alginate-g-polyacrylic acid/polyvinylpyrrolidone/gelatin granular hydrogel for $\mathrm{Cu}(\mathrm{II})$ ion was the highest. The recovery ability of sodium alginate-gpolyacrylic acid/polyvinylpyrrolidone/gelatin granular hydrogel was increased with increased in the hydrogel dosage. For $2.8 \mathrm{~g} \mathrm{~L}^{-1}$ dosage, reported recovery percentages were $90.92(\mathrm{Cu}(\mathrm{II}))$, $87.70(\mathrm{Ni}(\mathrm{II})), 87.47(\mathrm{Zn}(\mathrm{II}))$ and $85.55(\mathrm{Cd}(\mathrm{II})$. 
Gao et al., have produced hydrogel composite composed of sodium alginate, sodium acrylate and medical stone (Gao et al., 2011). Various heavy metal ions (Ni(II), $\mathrm{Cu}(\mathrm{II}), \mathrm{Zn}$ (II) and $\mathrm{Cd}(\mathrm{II})$ ) were removed by using sodium alginate-g-sodium acrylate/medical stone hydrogel composite. A smooth and non-porous surface was shown by sodium alginate-g-sodium acrylate hydrogel (Figure 18a) whereas medical stone exhibited rough and sheet surface (Figure 18b). The rough surface with pores and gap was formed on the addition of medical stone into sodium alginate-gsodium acrylate hydrogen (Figure 18c). It was analyzed that surface roughness was increased with increase in medical stone amount in sodium alginate-g-sodium acrylate/medical stone hydrogel composite (Figure 18d). Equilibrium heavy metal ions adsorption capacities for active carbon, medical stone and hydrogel composite with different amounts of medical stone were examined. The adsorption capacities for hydrogel composite with different amount of medical stone were found to be higher in comparison to active carbon and medical stone. Many carboxylate groups in hydrogel composite were found to form complexes with heavy metal ions during adsorption process.

Alginate/reduced graphene oxide double network hydrogel nano-composite was developed using facile method by Zhuang et al. (Zhuang et al., 2016). An adsorption capacity of $169.5 \mathrm{mg} \mathrm{g}^{-1}$ and $72.5 \mathrm{mg} \mathrm{g}^{-1}$ was reported for $\mathrm{Cu}(\mathrm{II})$ and $\mathrm{Cr}_{2} \mathrm{O}_{7}{ }^{2-}$ respectively by utilizing alginate/reduced graphene oxide double network hydrogel nano-composite. The schematic representation of hydrogel synthesis is presented in Figure 19. The reduced graphene oxide was formed by reduction of graphene oxide and alginate beads were developed through the addition of sodium alginate liquid into the $\mathrm{CaCl}_{2}$ solution. Three dimensional networks of alginate and two dimensional networks of graphene oxide were produced from the alginate/graphene composite. Another three dimensional interpenetrates networks were formed by reduced graphene oxide, 
which led to the formation of double network (Figure 20). Many particles like morphologies were observed in the SEM image of graphene-alginate single networks (Figure 20a), while alginate/reduced graphene oxide double-network has shown petal-like morphology (Figure 20b). The particle morphology of graphene-alginate single networks was not in accordance with oxygen element distribution (Figure 20c) whereas morphology of alginate/reduced graphene oxide double-network was in accordance with oxygen distribution (Figure 20d). Hence, it was concluded that hydrogen bonds played a crucial role in the production of three dimensional networks by reduced graphene oxide. The hydrogen bonding between reduced graphene oxide and alginate led to formation of uniform structure of graphene-alginate single networks, while hydrogen bonding among the sheets of graphene led to the development of three dimensional networks in reduced graphene oxide. In this work, the researchers have concluded that double network structure in prepared hydrogel composite enhanced the adsorption capacity as well as provided the evidences of repeated usage after many cycles of chemisorptions.

Tally et al., have synthesized sodium alginate-g-poly(acrylic acid-co-acrylamide) hydrogel by utilizing microwave oven (Tally and Atassi, 2016). An adsorption capacity of $480.77 \mathrm{mg} \mathrm{g}^{-1}$ has been reported for $\mathrm{Pb}$ (II) ion removal using sodium alginate-g-poly(acrylic acid-coacrylamide)hydrogel. Adsorption of $\mathrm{Cd}(\mathrm{II}), \mathrm{Ni}(\mathrm{II})$ and $\mathrm{Cu}(\mathrm{II})$ by sodium alginate-g-poly(acrylic acid-co-acrylamide) hydrogel has been also analyzed. Sodium n-dodecyl benzenesulfonate was used to produce pore forming micelles in sodium alginate-g-poly(acrylic acid-co-acrylamide) hydrogel. Spherical micelles were formed by sodium n-dodecyl benzenesulfonate at fixed concentration, which were introduced in the sodium alginate-g-poly(acrylic acid-co-acrylamide) hydrogel network. After washing, sodium n-dodecyl benzenesulfonate micelles were removed, which led to the formation of pores in sodium alginate-g-poly(acrylic acid-co-acrylamide) 
hydrogel (Figure 21). Figure 22 represents XRD spectra for alginate, poly(acrylic acid-coacrylamide) and sodium alginate-g-poly(acrylic acid-co-acrylamide) hydrogel. The crystalline nature was decreased on grafting of copolymer on sodium alginate. This behavior was affirmed from the broader peak at $17^{\circ}-37^{\circ}$ in the XRD spectra of sodium alginate-g-poly(acrylic acid-coacrylamide) hydrogel (Figure 22).

In another study, blending was used to develop sodium alginate-carboxymethyl cellulose gel beads (Ren et al., 2016). The synthesized gel bead was used to remove $\mathrm{Pb}$ (II) ion from aqueous solution. Adsorption percentage of more than 99 was reported for $\mathrm{Pb}(\mathrm{II})$ ion by using sodium alginate-carboxymethyl cellulose gel bead. The wrinkled and low porosity structure was exhibited by the pure sodium alginate gel bead (Figure 23a), whereas rough and highly porous structure was shown by sodium alginate-carboxymethyl cellulose gel bead (Figure 23b). High surface area and porosity was displayed by cross section of sodium alginate-carboxymethyl cellulose gel bead (Figure 23c). Internal network of sodium alginate-carboxymethyl cellulose gel bead developed through the condensation reaction among hydroxyls groups of carboxymethyl cellulose and carboxyl groups of sodium alginate. Sodium alginatecarboxymethyl cellulose gel bead was found to be more efficient than cation exchange resin and activated carbon for lead ions removal. The lead ion removal percentages were $99.6 \%, 74.8 \%$ and $66.4 \%$ for sodium alginate-carboxymethyl cellulose gel bead, cation exchange resin and activated carbon respectively.

\section{Conclusion}

In this article, we have reviewed a versatile class of sodium alginate based hydrogels that are potentially useful for creating multitasking systems intended for achieving advanced adsorption properties. Hydrogels integrated with nano-particles, which not only increase the mechanical 
characteristics of the hydrogels but also modulate its adsorption behavior, appear more efficiently. Hydrogel nano-composite materials manifest stimuli-responsive properties including photo thermal activity, catalysis, target drug delivery, anti-microbial property, drug degradation, removal of aquatic pollutants, bio-sensing and many more which makes it ideal for "smart" material. Our prime emphasis has been to bring potential design parameters useful for adsorption of pollutants. The systematic investigation on hydrogel composites for water purification application can persuade more research efforts to label the challenges and upgrade an area of interest for the general study of hydrogels. There is still a need for further investigations targeting on the intrinsic interactions of nano-particles with polymer matrix in order to alter their properties to explore more scientific research.

\section{Acknowledgement}

Dr Sourbh Thakur acknowledges financial support by Postdoctoral Fellowship project No 09.3.3-LMT-K-712-02-0180 and project 09.3.3-LMT-K-712 'Development of Scientific Competences of Scientists, other Researchers and Students through Practical Research Activities' (Funding instrument - European Social Fund). Dr Sourbh Thakur is also thankful to Kaunas University of Technology.

\section{References}

A Bhosale, M., M Bhanage, B., 2015. Silver nanoparticles: Synthesis, characterization and their application as a sustainable catalyst for organic transformations. Current Organic Chemistry 19, 708-727.

Ahmed, E.M., 2015. Hydrogel: Preparation, characterization, and applications: A review. Journal of advanced research $6,105-121$. 
Awual, M.R., Hasan, M.M., Ihara, T., Yaita, T., 2014. Mesoporous silica based novel conjugate adsorbent for efficient selenium (IV) detection and removal from water. Microporous and Mesoporous Materials 197, 331-338.

Awual, M.R., Hasan, M.M., Khaleque, M.A., 2015. Efficient selenium (IV) detection and removal from water by tailor-made novel conjugate adsorbent. Sensors and Actuators B: Chemical 209, 194-202.

Belhouchat, N., Zaghouane-Boudiaf, H., Viseras, C., 2017. Removal of anionic and cationic dyes from aqueous solution with activated organo-bentonite/sodium alginate encapsulated beads. Applied Clay Science 135, 9-15.

Bhattacharyya, R., Ray, S.K., 2015. Adsorption of industrial dyes by semi-IPN hydrogels of acrylic copolymers and sodium alginate. Journal of Industrial and Engineering Chemistry $22,92-102$.

Bouhadir, K.H., Lee, K.Y., Alsberg, E., Damm, K.L., Anderson, K.W., Mooney, D.J., 2001. Degradation of partially oxidized alginate and its potential application for tissue engineering. Biotechnology progress 17, 945-950.

Buchholz, F.L., Graham, A.T., 1998. Modern superabsorbent polymer technology. John! Wiley \& Sons, Inc, 605 Third Ave, New York, NY 10016, USA, 1998. 279.

Burkert, S., Schmidt, T., Gohs, U., Dorschner, H., Arndt, K.-F., 2007. Cross-linking of poly (Nvinyl pyrrolidone) films by electron beam irradiation. Radiation Physics and Chemistry $76,1324-1328$.

Caló, E., Khutoryanskiy, V.V., 2015. Biomedical applications of hydrogels: A review of patents and commercial products. European Polymer Journal 65, 252-267. 
Can, V., Abdurrahmanoglu, S., Okay, O., 2007. Unusual swelling behavior of polymer-clay nanocomposite hydrogels. Polymer 48, 5016-5023.

Chan, L.W., Lee, H.Y., Heng, P.W., 2006. Mechanisms of external and internal gelation and their impact on the functions of alginate as a coat and delivery system. Carbohydrate Polymers 63, 176-187.

Chiew, C.S.C., Yeoh, H.K., Pasbakhsh, P., Poh, P.E., Tey, B.T., Chan, E.S., 2016. Stability and reusability of alginate-based adsorbents for repetitive lead (II) removal. Polymer Degradation and Stability 123, 146-154.

de Vos, P., Faas, M.M., Strand, B., Calafiore, R., 2006. Alginate-based microcapsules for immunoisolation of pancreatic islets. Biomaterials 27, 5603-5617.

Donati, I., Vetere, A., Gamini, A., Skjla ak-Brla ek, G., Coslovi, A., Campa, C., Paoletti, S., 2003. Galactose-substituted alginate: preliminary characterization and study of gelling properties. Biomacromolecules 4, 624-631.

Du, X., Zhou, J., Shi, J., Xu, B., 2015. Supramolecular hydrogelators and hydrogels: from soft matter to molecular biomaterials. Chem. Rev 115, 13165-13307.

Eghbalifam, N., Frounchi, M., Dadbin, S., 2015. Antibacterial silver nanoparticles in polyvinyl alcohol/sodium alginate blend produced by gamma irradiation. International Journal of Biological Macromolecules 80, 170-176.

El-Sherbiny, I.M., 2010. Enhanced pH-responsive carrier system based on alginate and chemically modified carboxymethyl chitosan for oral delivery of protein drugs: preparation and in-vitro assessment. Carbohydrate Polymers 80, 1125-1136. 
Fan, J., Shi, Z., Lian, M., Li, H., Yin, J., 2013. Mechanically strong graphene oxide/sodium alginate/polyacrylamide nanocomposite hydrogel with improved dye adsorption capacity. Journal of Materials Chemistry A 1,7433-7443.

Fane, A.G., Wang, R., Hu, M.X., 2015. Synthetic membranes for water purification: status and future. Angewandte Chemie International Edition 54, 3368-3386.

Fatin-Rouge, N., Dupont, A., Vidonne, A., Dejeu, J., Fievet, P., Foissy, A., 2006. Removal of some divalent cations from water by membrane-filtration assisted with alginate. Water Research 40, 1303-1309.

Franklin, M.J., Ohman, D.E., 2002. Mutant analysis and cellular localization of the AlgI, AlgJ, and $\mathrm{AlgF}$ proteins required for $\mathrm{O}$ acetylation of alginate in Pseudomonas aeruginosa. Journal of bacteriology 184, 3000-3007.

Galant, C., Kjøniksen, A.-L., Nguyen, G.T., Knudsen, K.D., Nyström, B., 2006. Altering associations in aqueous solutions of a hydrophobically modified alginate in the presence of $\beta$-cyclodextrin monomers. The Journal of Physical Chemistry B 110, 190-195.

Gao, T., Wang, W., Wang, A., 2011. A pH-sensitive composite hydrogel based on sodium alginate and medical stone: synthesis, swelling, and heavy metal ions adsorption properties. Macromolecular research 19, 739-748.

Goh, C.H., Heng, P.W.S., Chan, L.W., 2012. Alginates as a useful natural polymer for microencapsulation and therapeutic applications. Carbohydrate Polymers 88, 1-12.

Guilherme, M.R., Reis, A.V., Takahashi, S.H., Rubira, A.F., Feitosa, J.P.A., Muniz, E.C., 2005. Synthesis of a novel superabsorbent hydrogel by copolymerization of acrylamide and cashew gum modified with glycidyl methacrylate. Carbohydrate Polymers 61, 464-471. https://doi.org/10.1016/j.carbpol.2005.06.017 
Han, L., Lu, X., Wang, M., Gan, D., Deng, W., Wang, K., Fang, L., Liu, K., Chan, C.W., Tang, Y., 2017. A Mussel-Inspired Conductive, Self-Adhesive, and Self-Healable Tough Hydrogel as Cell Stimulators and Implantable Bioelectronics. Small 13.

Heidarizad, M., Şengör, S.S., 2016. Synthesis of graphene oxide/magnesium oxide nanocomposites with high-rate adsorption of methylene blue. Journal of Molecular Liquids 224, 607-617.

Higuchi, A., Ling, Q.-D., Chang, Y., Hsu, S.-T., Umezawa, A., 2013. Physical cues of biomaterials guide stem cell differentiation fate. Chemical reviews 113, 3297-3328.

Hosseinzadeh, H., Abdi, K., 2017. Efficient Removal of Methylene Blue Using a Hybrid Organic-Inorganic Hydrogel Nanocomposite Adsorbent Based on Sodium AlginateSilicone Dioxide. Journal of Inorganic and Organometallic Polymers and Materials 27, $1595-1612$.

Izawa, H., Kadokawa, J., 2010. Preparation and characterizations of functional ionic liquid-gel and hydrogel materials of xanthan gum. Journal of Materials Chemistry 20, 5235-5241.

Jeon, O., Bouhadir, K.H., Mansour, J.M., Alsberg, E., 2009. Photocrosslinked alginate hydrogels with tunable biodegradation rates and mechanical properties. Biomaterials 30, 27242734.

Kaith, B.S., Jindal, R., Kumar, V., 2015. Biodegradation of Gum tragacanth acrylic acid based hydrogel and its impact on soil fertility. Polymer Degradation and Stability 115, 24-31.

Kamata, H., Li, X., Chung, U., Sakai, T., 2015. Design of hydrogels for biomedical applications. Advanced healthcare materials 4, 2360-2374. 
Karadağ, E., Saraydın, D., Güven, O., 2001. Radiation induced superabsorbent hydrogels. Acrylamide/itaconic acid copolymers. Macromolecular Materials and Engineering 286, $34-42$.

Karthiga Devi, G., Senthil Kumar, P., Sathish Kumar, K., 2016. Green synthesis of novel silver nanocomposite hydrogel based on sodium alginate as an efficient biosorbent for the dye wastewater treatment: prediction of isotherm and kinetic parameters. Desalination and Water Treatment 57, 27686-27699.

Khan, M., Lo, I.M., 2016a. A holistic review of hydrogel applications in the adsorptive removal of aqueous pollutants: Recent progress, challenges, and perspectives. Water research 106, 259-271.

Khan, M., Lo, I.M., 2016b. A holistic review of hydrogel applications in the adsorptive removal of aqueous pollutants: recent progress, challenges, and perspectives. Water research 106, $259-271$.

Khotimchenko, Y.S., Kovalev, V.V., Savchenko, O.V., Ziganshina, O.A., 2001. Physicalchemical properties, physiological activity, and usage of alginates, the polysaccharides of brown algae. Russian Journal of Marine Biology 27, S53-S64.

Kim, D.Y., Kwon, D.Y., Kwon, J.S., Kim, J.H., Min, B.H., Kim, M.S., 2015. Stimuli-responsive injectable in situ-forming hydrogels for regenerative medicines. Polymer Reviews 55, $407-452$.

Kim, J.-H., Randall Lee, T., 2006. Discrete thermally responsive hydrogel-coated gold nanoparticles for use as drug-delivery vehicles. Drug development research 67, 61-69. 
Kim, Y.-J., Yoon, K.-J., Ko, S.-W., 2000. Preparation and properties of alginate superabsorbent filament fibers crosslinked with glutaraldehyde. Journal of Applied Polymer Science 78, $1797-1804$.

Knipe, J.M., Chen, F., Peppas, N.A., 2015. Enzymatic biodegradation of hydrogels for protein delivery targeted to the small intestine. Biomacromolecules 16, 962-972.

Lakouraj, M.M., Mojerlou, F., Zare, E.N., 2014. Nanogel and superparamagnetic nanocomposite based on sodium alginate for sorption of heavy metal ions. Carbohydrate polymers 106, $34-41$.

Lam, W.-H., Chong, M.N., Horri, B.A., Tey, B.-T., Chan, E.-S., 2017. Physicochemical stability of calcium alginate beads immobilizing $\mathrm{TiO} 2$ nanoparticles for removal of cationic dye under UV irradiation. Journal of Applied Polymer Science 134.

Lee, K.Y., Mooney, D.J., 2012. Alginate: properties and biomedical applications. Progress in polymer science $37,106-126$.

Lee, K.Y., Mooney, D.J., 2001. Hydrogels for tissue engineering. Chemical reviews 101, 18691880.

Li, Y., Huang, G., Zhang, X., Li, B., Chen, Y., Lu, T., Lu, T.J., Xu, F., 2013. Magnetic hydrogels and their potential biomedical applications. Advanced Functional Materials 23, 660-672.

Li, Y., Rodrigues, J., Tomas, H., 2012. Injectable and biodegradable hydrogels: gelation, biodegradation and biomedical applications. Chemical Society Reviews 41, 2193-2221.

Liu, J., Su, D., Yao, J., Huang, Y., Shao, Z., Chen, X., 2017. Soy protein-based polyethylenimine hydrogel and its high selectivity for copper ion removal in wastewater treatment. Journal of Materials Chemistry A 5, 4163-4171. 
Lu, T., Xiang, T., Huang, X.-L., Li, C., Zhao, W.-F., Zhang, Q., Zhao, C.-S., 2015. Postcrosslinking towards stimuli-responsive sodium alginate beads for the removal of dye and heavy metals. Carbohydrate polymers 133, 587-595.

Ma, M., Kuang, Y., Gao, Y., Zhang, Y., Gao, P., Xu, B., 2010. Aromatic- aromatic interactions induce the self-assembly of pentapeptidic derivatives in water to form nanofibers and supramolecular hydrogels. Journal of the American Chemical Society 132, 2719-2728.

Mahdavinia, G.R., Aghaie, H., Sheykhloie, H., Vardini, M.T., Etemadi, H., 2013. Synthesis of CarAlg/MMt nanocomposite hydrogels and adsorption of cationic crystal violet. Carbohydrate polymers 98, 358-365.

Mahdavinia, G.R., Mousanezhad, S., Hosseinzadeh, H., Darvishi, F., Sabzi, M., 2016. Magnetic hydrogel beads based on PVA/sodium alginate/laponite RD and studying their BSA adsorption. Carbohydrate polymers 147, 379-391.

Mehrali, M., Thakur, A., Pennisi, C.P., Talebian, S., Arpanaei, A., Nikkhah, M., DolatshahiPirouz, A., 2017. Nanoreinforced Hydrogels for Tissue Engineering: Biomaterials that are Compatible with Load-Bearing and Electroactive Tissues. Advanced Materials 29.

Merino, S., Martín, C., Kostarelos, K., Prato, M., Vázquez, E., 2015. Nanocomposite hydrogels: 3D polymer-nanoparticle synergies for on-demand drug delivery. ACS nano 9, 46864697.

Nayak, A.K., Malakar, J., Sen, K.K., 2010. Gastroretentive drug delivery technologies: Current approaches and future potential. Journal of Pharmaceutical Education and Research 1, 1.

Ngah, W.W., Fatinathan, S., 2008. Adsorption of Cu (II) ions in aqueous solution using chitosan beads, chitosan-GLA beads and chitosan-alginate beads. Chemical Engineering Journal $143,62-72$. 
Oh, J.Y., Rondeau-Gagné, S., Chiu, Y.-C., Chortos, A., Lissel, F., Wang, G.-J.N., Schroeder, B.C., Kurosawa, T., Lopez, J., Katsumata, T., 2016. Intrinsically stretchable and healable semiconducting polymer for organic transistors. Nature 539, 411.

Omidian, H., Rocca, J.G., Park, K., 2006. Elastic, superporous hydrogel hybrids of polyacrylamide and sodium alginate. Macromolecular bioscience 6, 703-710.

Paddon, C.J., Westfall, P.J., Pitera, D.J., Benjamin, K., Fisher, K., McPhee, D., Leavell, M.D., Tai, A., Main, A., Eng, D., 2013. High-level semi-synthetic production of the potent antimalarial artemisinin. Nature 496, 528-532.

Pakdel, P.M., Peighambardoust, S.J., 2018. A review on acrylic based hydrogels and their applications in wastewater treatment. Journal of environmental management 217, 123143.

Paques, J.P., van der Linden, E., van Rijn, C.J., Sagis, L.M., 2014. Preparation methods of alginate nanoparticles. Advances in colloid and interface science 209, 163-171.

Pardo-Yissar, V., Gabai, R., Shipway, A.N., Bourenko, T., Willner, I., 2001. Gold Nanoparticle/Hydrogel Composites with Solvent-Switchable Electronic Properties. Advanced Materials 13, 1320-1323.

Park, J.H., Kim, D., 2001. Study on foaming water-swellable EPDM rubber. J Appl Polym Sci $80,115-21$.

Pawar, S.N., Edgar, K.J., 2012a. Alginate derivatization: a review of chemistry, properties and applications. Biomaterials 33, 3279-3305.

Pawar, S.N., Edgar, K.J., 2012b. Alginate derivatization: A review of chemistry, properties and $\begin{array}{llll}\text { applications. } & \text { Biomaterials } & 33, & 3279-3305 \text {. }\end{array}$ https://doi.org/10.1016/j.biomaterials.2012.01.007 
Pereira, R., Carvalho, A., Vaz, D.C., Gil, M.H., Mendes, A., Bártolo, P., 2013. Development of novel alginate based hydrogel films for wound healing applications. International journal of biological macromolecules 52, 221-230.

Pourjavadi, A., Doulabi, M., Doroudian, M., 2014. Adsorption characteristics of malachite green dye onto novel kappa-carrageenan-g-polyacrylic acid/TiO2-NH2 hydrogel nanocomposite. Journal of the Iranian Chemical Society 11, 1057-1065.

Pourjavadi, A., Farhadpour, B., Seidi, F., 2008. Synthesis and investigation of swelling behavior of grafted alginate/alumina superabsorbent composite. Starch-Stärke 60, 457-466.

Qiu, Y., Park, K., 2001. Environment-sensitive hydrogels for drug delivery. Advanced drug delivery reviews 53, 321-339.

Rashidzadeh, A., Olad, A., Salari, D., 2015. The effective removal of methylene blue dye from aqueous solutions by NaAlg-g-poly (acrylic acid-co-acryl amide)/clinoptilolite hydrogel nanocomposite. Fibers and Polymers 16, 354-362.

Reis, A.V., Fajardo, A.R., Schuquel, I.T., Guilherme, M.R., Vidotti, G.J., Rubira, A.F., Muniz, E.C., 2009. Reaction of glycidyl methacrylate at the hydroxyl and carboxylic groups of poly (vinyl alcohol) and poly (acrylic acid): is this reaction mechanism still unclear? The Journal of organic chemistry $74,3750-3757$.

Ren, H., Gao, Z., Wu, D., Jiang, J., Sun, Y., Luo, C., 2016. Efficient Pb (II) removal using sodium alginate-carboxymethyl cellulose gel beads: preparation, characterization, and adsorption mechanism. Carbohydrate polymers 137, 402-409.

rights are reserved by Shivani, A., Shetye, P., n.d. Hydrogels: Introduction, Preparation, Characterization and Applications. 
Rosales, A.M., Anseth, K.S., 2016. The design of reversible hydrogels to capture extracellular matrix dynamics. Nature Reviews Materials 1, 15012.

Roy, D., Cambre, J.N., Sumerlin, B.S., 2010. Future perspectives and recent advances in stimuliresponsive materials. Progress in Polymer Science 35, 278-301.

Sahiner, N., 2013. Soft and flexible hydrogel templates of different sizes and various functionalities for metal nanoparticle preparation and their use in catalysis. Progress in Polymer Science 38, 1329-1356.

Sahiner, N., Seven, F., 2014. The use of superporous p (AAc (acrylic acid)) cryogels as support for $\mathrm{Co}$ and $\mathrm{Ni}$ nanoparticle preparation and as reactor in $\mathrm{H} 2$ production from sodium borohydride hydrolysis. Energy 71, 170-179.

Saravanan, P., Raju, M.P., Alam, S., 2007. A study on synthesis and properties of Ag nanoparticles immobilized polyacrylamide hydrogel composites. Materials chemistry and physics $103,278-282$.

Seliktar, D., 2012. Designing cell-compatible hydrogels for biomedical applications. Science $336,1124-1128$.

Sershen, S.R., Westcott, S.L., Halas, N.J., West, J.L., 2002. Independent optically addressable nanoparticle-polymer optomechanical composites. Applied Physics Letters 80, 46094611.

Shetye, S.P., Godbole, A., Bhilegaokar, S., Gajare, P., 2015. Hydrogels: Introduction, Preparation, Characterization and Applications. Hum. J 1, 47-71.

Shi, J., Gao, Y., Yang, Z., Xu, B., 2011. Exceptionally small supramolecular hydrogelators based on aromatic-aromatic interactions. Beilstein journal of organic chemistry 7, 167. 
Shin, S.R., Bae, H., Cha, J.M., Mun, J.Y., Chen, Y.-C., Tekin, H., Shin, H., Farshchi, S., Dokmeci, M.R., Tang, S., 2011. Carbon nanotube reinforced hybrid microgels as scaffold materials for cell encapsulation. ACS nano 6, 362-372.

Talaat, H.A., Sorour, M.H., Aboulnour, A.G., Shaalan, H.F., Ahmed, E.M., Awad, A.M., Ahmed, M.A., 2008. Development of a multi-component fertilizing hydrogel with relevant techno-economic indicators. Am-Euras J Agric Environ Sci 3, 764-70.

Tally, M., Atassi, Y., 2016. Synthesis and characterization of pH-sensitive superabsorbent hydrogels based on sodium alginate-g-poly (acrylic acid-co-acrylamide) obtained via an anionic surfactant micelle templating under microwave irradiation. Polymer Bulletin 73, 3183-3208.

Thakur, M.K., Thakur, V.K., Gupta, R.K., Pappu, A., 2015. Synthesis and applications of biodegradable soy based graft copolymers: a review. ACS Sustainable Chemistry \& Engineering 4, 1-17.

Thakur, S., 2016. Sodium alginate, xanthan gum biopolymer composites: synthesis, characterisation and application in organic dye removal from water ( $\mathrm{PhD}$ Thesis). University of Johannesburg.

Thakur, S., Arotiba, O., 2017. Synthesis, characterization and adsorption studies of an acrylic acid-grafted sodium alginate-based $\mathrm{TiO} 2$ hydrogel nanocomposite. Adsorption Science \& Technology 0263617417700636.

Thakur, S., Arotiba, O.A., n.d. Synthesis, swelling and adsorption studies of a pH-responsive sodium alginate-poly (acrylic acid) superabsorbent hydrogel. Polymer Bulletin 1-20.

Thakur, S., Arotiba, O.A., n.d. Synthesis, swelling and adsorption studies of a pH-responsive sodium alginate-poly (acrylic acid) superabsorbent hydrogel. Polymer Bulletin 1-20. 
Thakur, S., Govender, P.P., Mamo, M.A., Tamulevicius, S., Mishra, Y.K., Thakur, V.K., 2017a. Progress in lignin hydrogels and nanocomposites for water purification: Future perspectives. Vacuum 146, 342-355.

Thakur, S., Govender, P.P., Mamo, M.A., Tamulevicius, S., Thakur, V.K., 2017b. Recent progress in gelatin hydrogel nanocomposites for water purification and beyond. Vacuum $146,396-408$.

Thakur, S., Pandey, S., Arotiba, O.A., 2016. Development of a sodium alginate-based organic/inorganic superabsorbent composite hydrogel for adsorption of methylene blue. Carbohydrate polymers 153, 34-46.

Thoniyot, P., Tan, M.J., Karim, A.A., Young, D.J., Loh, X.J., 2015a. Nanoparticle-hydrogel composites: Concept, design, and applications of these promising, multi-functional materials. Advanced Science 2.

Thoniyot, P., Tan, M.J., Karim, A.A., Young, D.J., Loh, X.J., 2015b. Nanoparticle-hydrogel composites: Concept, design, and applications of these promising, multi-functional materials. Advanced Science 2.

Uto, K., Tsui, J.H., DeForest, C.A., Kim, D.-H., 2017. Dynamically tunable cell culture platforms for tissue engineering and mechanobiology. Progress in polymer science 65, $53-82$.

Vermonden, T., Censi, R., Hennink, W.E., 2012a. Hydrogels for protein delivery. Chemical Reviews 112, 2853-2888.

Vermonden, T., Censi, R., Hennink, W.E., 2012b. Hydrogels for protein delivery. Chemical Reviews 112, 2853-2888. 
Vivek, B., Prasad, E., 2015. Reusable self-healing hydrogels realized via in situ polymerization. The Journal of Physical Chemistry B 119, 4881-4887.

Wang, C., Flynn, N.T., Langer, R., 2004. Controlled structure and properties of thermoresponsive nanoparticle-hydrogel composites. Advanced Materials 16, 10741079.

Wang, C., Wu, H., Chen, Z., McDowell, M.T., Cui, Y., Bao, Z., 2013. Self-healing chemistry enables the stable operation of silicon microparticle anodes for high-energy lithium-ion batteries. Nature chemistry 5, 1042-1048.

Wang, L., Zhang, J., Wang, A., 2008. Removal of methylene blue from aqueous solution using chitosan-g-poly (acrylic acid)/montmorillonite superadsorbent nanocomposite. Colloids and Surfaces A: Physicochemical and Engineering Aspects 322, 47-53.

Wang, W., Kang, Y., Wang, A., 2013a. One-step fabrication in aqueous solution of a granular alginate-based hydrogel for fast and efficient removal of heavy metal ions. Journal of Polymer Research 20, 101.

Wang, W., Zhang, Y., Liu, W., 2017. Bioinspired fabrication of high strength hydrogels from non-covalent interactions. Progress in Polymer Science 71, 1-25.

Wang, W., Zong, L., Wang, A., 2013b. A nanoporous hydrogel based on vinyl-functionalized alginate for efficient absorption and removal of $\mathrm{Pb} 2+$ ions. International journal of biological macromolecules 62, 225-231.

Wu, H., Yu, G., Pan, L., Liu, N., McDowell, M.T., Bao, Z., Cui, Y., 2013. Stable Li-ion battery anodes by in-situ polymerization of conducting hydrogel to conformally coat silicon nanoparticles. Nature communications 4, 1943. 
Wu, Y., Qi, H., Shi, C., Ma, R., Liu, S., Huang, Z., 2017. Preparation and adsorption behaviors of sodium alginate-based adsorbent-immobilized $\beta$-cyclodextrin and graphene oxide. RSC Advances 7, 31549-31557.

Yang, J.-A., Yeom, J., Hwang, B.W., Hoffman, A.S., Hahn, S.K., 2014. In situ-forming injectable hydrogels for regenerative medicine. Progress in Polymer Science 39, 19731986.

Yang, J.-S., Xie, Y.-J., He, W., 2011. Research progress on chemical modification of alginate: A review. Carbohydrate polymers 84, 33-39.

Yi, X., Sun, F., Han, Z., Han, F., He, J., Ou, M., Gu, J., Xu, X., 2018. Graphene oxide encapsulated polyvinyl alcohol/sodium alginate hydrogel microspheres for $\mathrm{Cu}$ (II) and $\mathrm{U}$ (VI) removal. Ecotoxicology and environmental safety 158, 309-318.

You, J.-O., Park, S.-B., Park, H.-Y., Haam, S., Chung, C.-H., Kim, W.-S., 2001. Preparation of regular sized Ca-alginate microspheres using membrane emulsification method. Journal of microencapsulation 18, 521-532.

Zhang, D., Yang, J., Bao, S., Wu, Q., Wang, Q., 2013. Semiconductor nanoparticle-based hydrogels prepared via self-initiated polymerization under sunlight, even visible light. Scientific Reports 3, 1399.

Zhao, F., Yao, D., Guo, R., Deng, L., Dong, A., Zhang, J., 2015. Composites of polymer hydrogels and nanoparticulate systems for biomedical and pharmaceutical applications. Nanomaterials 5, 2054-2130.

Zhao, L.Z., Zhou, C.H., Wang, J., Tong, D.S., Yu, W.H., Wang, H., 2015. Recent advances in clay mineral-containing nanocomposite hydrogels. Soft Matter 11, 9229-9246. 
Zhao, W., Jin, X., Cong, Y., Liu, Y., Fu, J., 2013. Degradable natural polymer hydrogels for articular cartilage tissue engineering. Journal of Chemical Technology and Biotechnology $88,327-339$.

Zhuang, Y., Yu, F., Chen, H., Zheng, J., Ma, J., Chen, J., 2016. Alginate/graphene doublenetwork nanocomposite hydrogel beads with low-swelling, enhanced mechanical properties, and enhanced adsorption capacity. Journal of Materials Chemistry A 4, $10885-10892$.

Zimmermann, U., Klöck, G., Federlin, K., Hannig, K., Kowalski, M., Bretzel, R.G., Horcher, A., Entenmann, H., Sieber, U., Zekorn, T., 1992. Production of mitogen-contamination free alginates with variable ratios of mannuronic acid to guluronic acid by free flow electrophoresis. Electrophoresis 13, 269-274.

Zuo, Y., Liu, X., Wei, D., Sun, J., Xiao, W., Zhao, H., Guo, L., Wei, Q., Fan, H., Zhang, X., 2015. Photo-cross-linkable methacrylated gelatin and hydroxyapatite hybrid hydrogel for modularly engineering biomimetic osteon. ACS applied materials \& interfaces 7, 1038610394. 


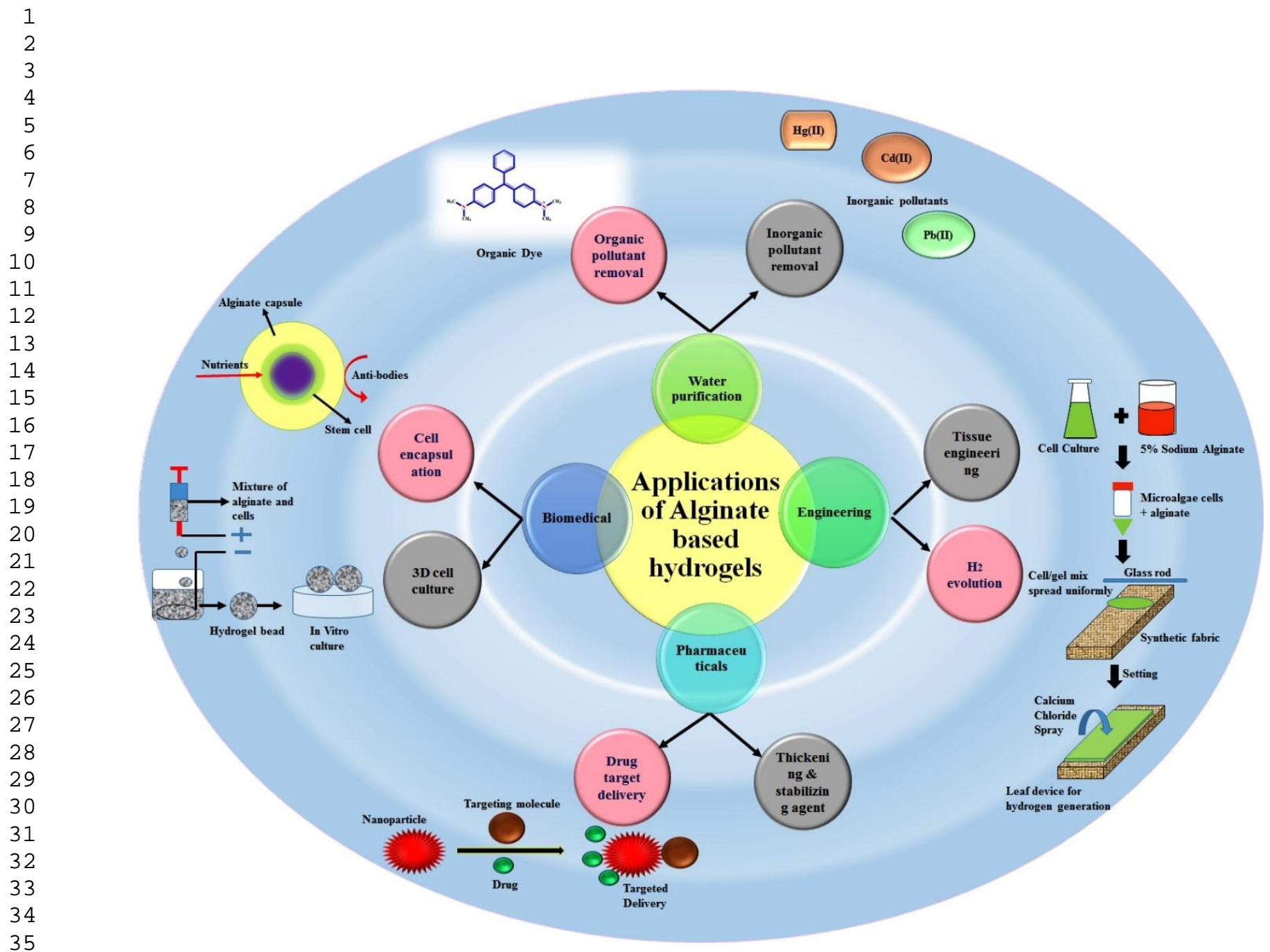

Figure 1. Various applied applications of alginate based hydrogels 


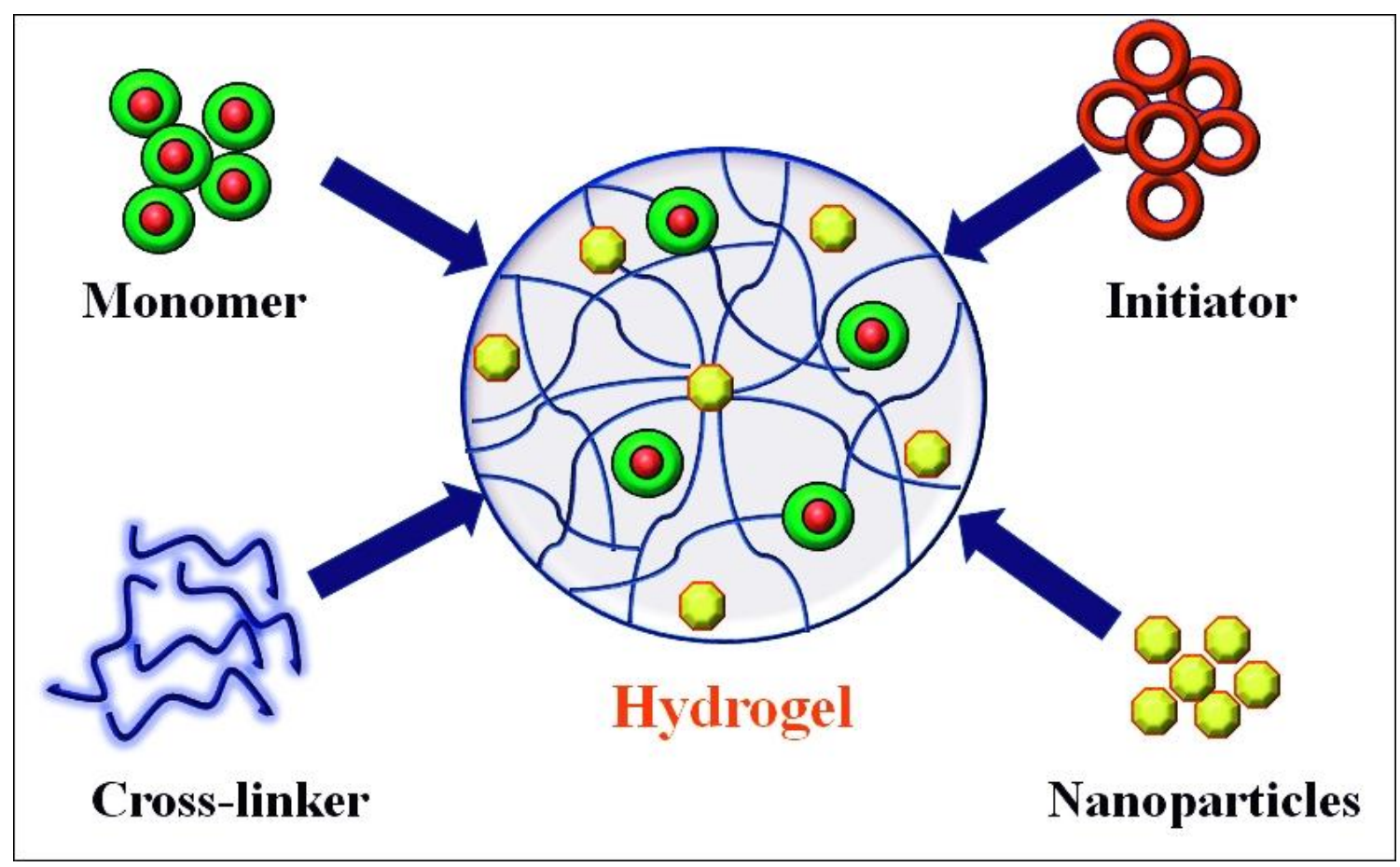

Figure 2. Schematic diagram of hydrogel preparation. 


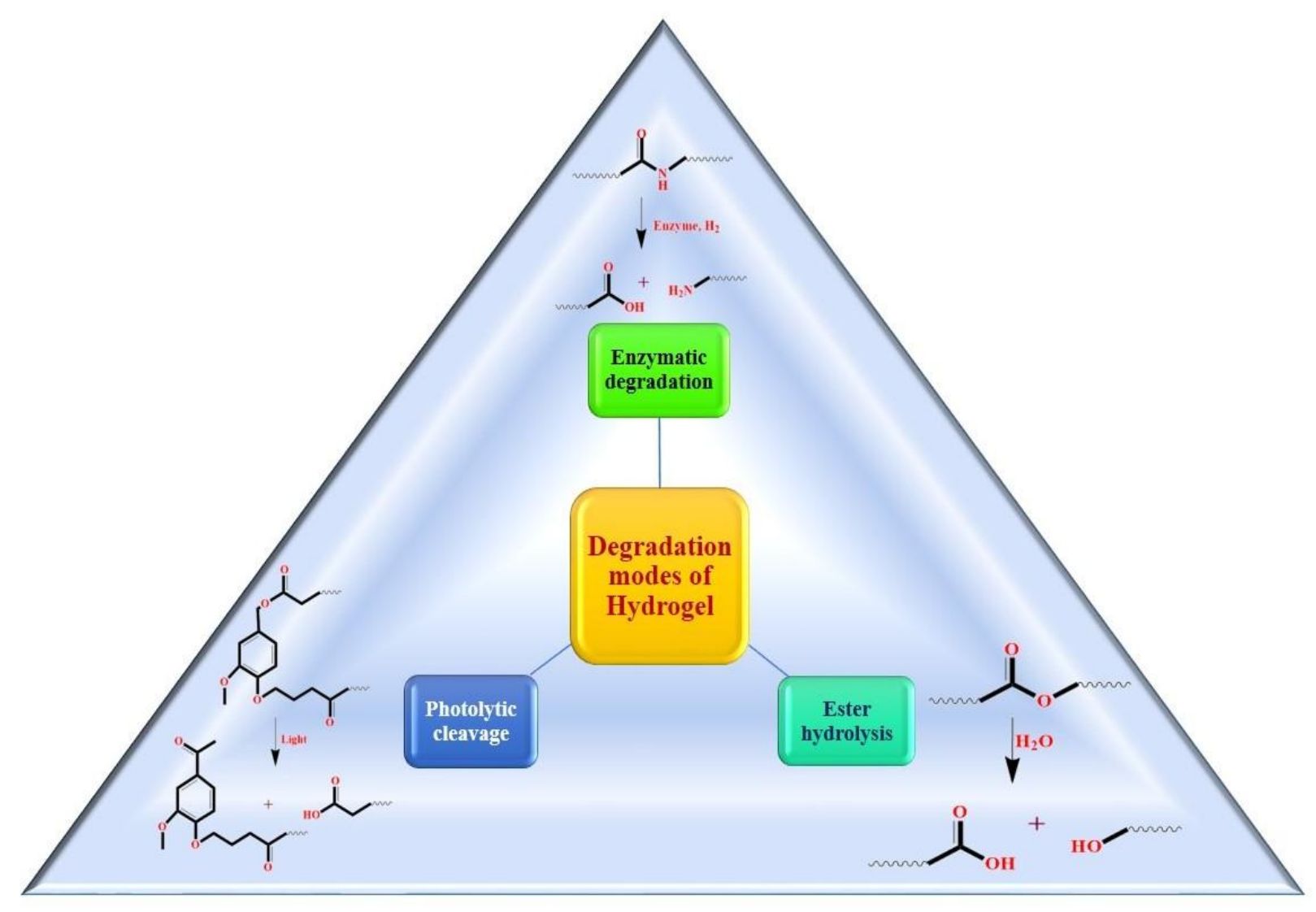

Figure 3. Different modes of degradation of hydrogel. 


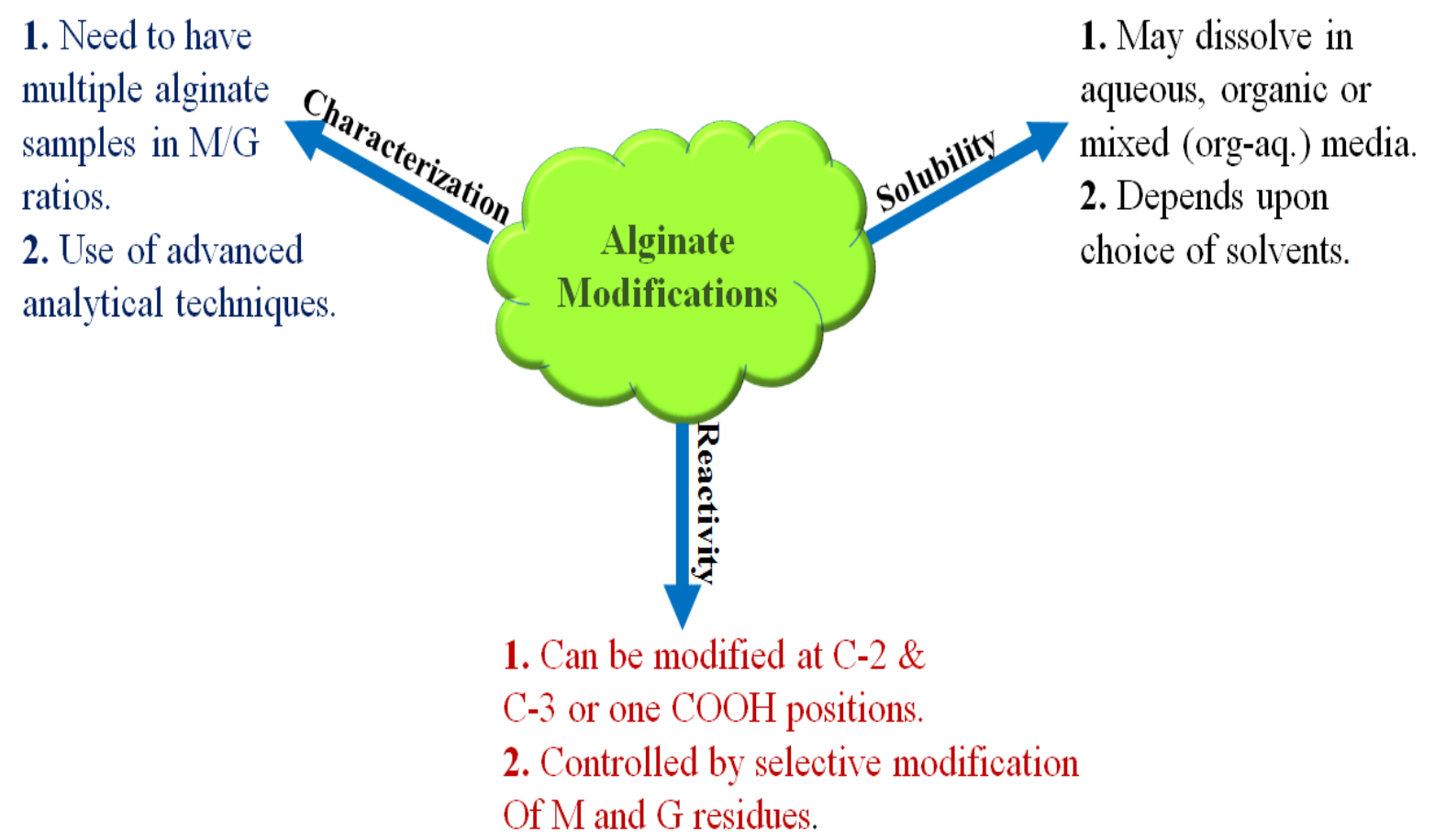

Figure 4. Parameters governing alginate derivatization. Adopted from (Pawar and Edgar, 2012). 


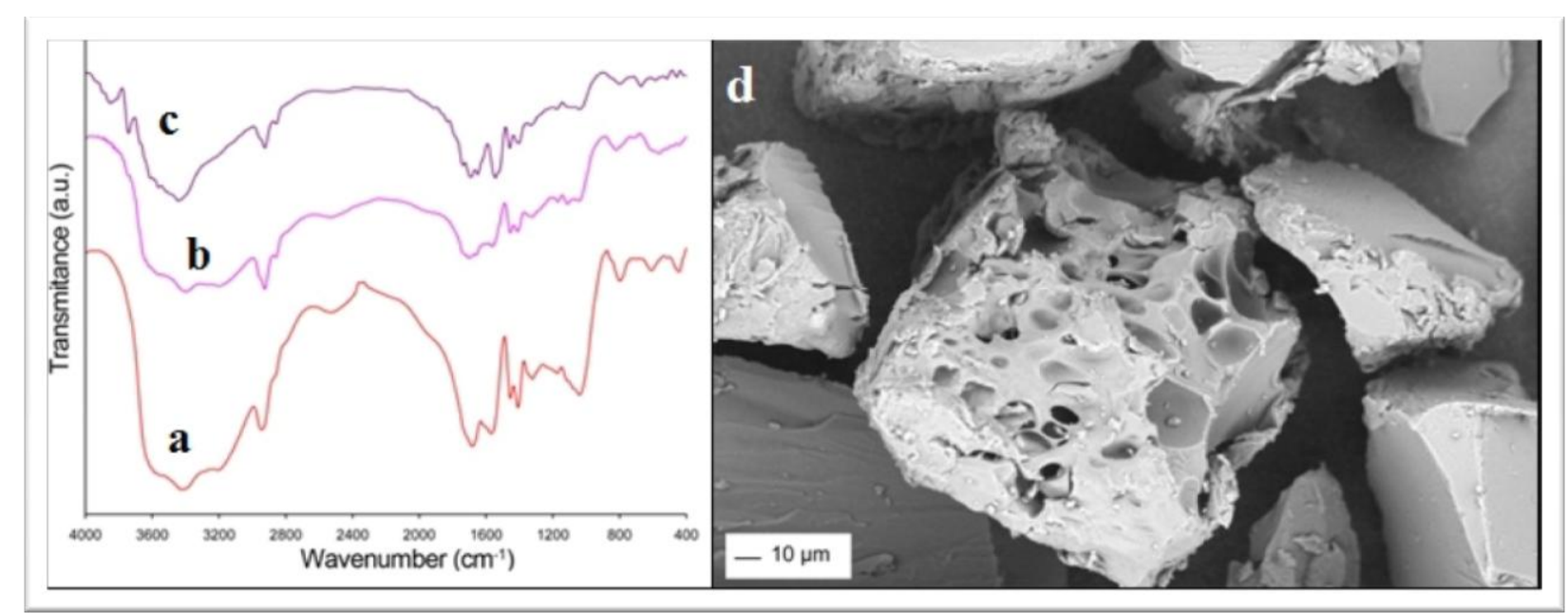

Figure 5. FTIR spectrum (a) sodium alginate-g-poly(acrylic acid-co-acryl amide)/clinoptilolite, (b) sodium alginate-g-poly(acrylic acid-co-acryl amide) and (c) methylene blue adsorbed sodium alginate-g-poly(acrylic acid-co-acryl amide)/clinoptilolite, (d) SEM morphology of sodium alginate-g-poly(acrylic acid-co-acryl amide)/clinoptilolite (Rashidzadeh et al., 2015). Reprinted with permission from (Rashidzadeh et al., 2015). Copyright 2015 Springer. 


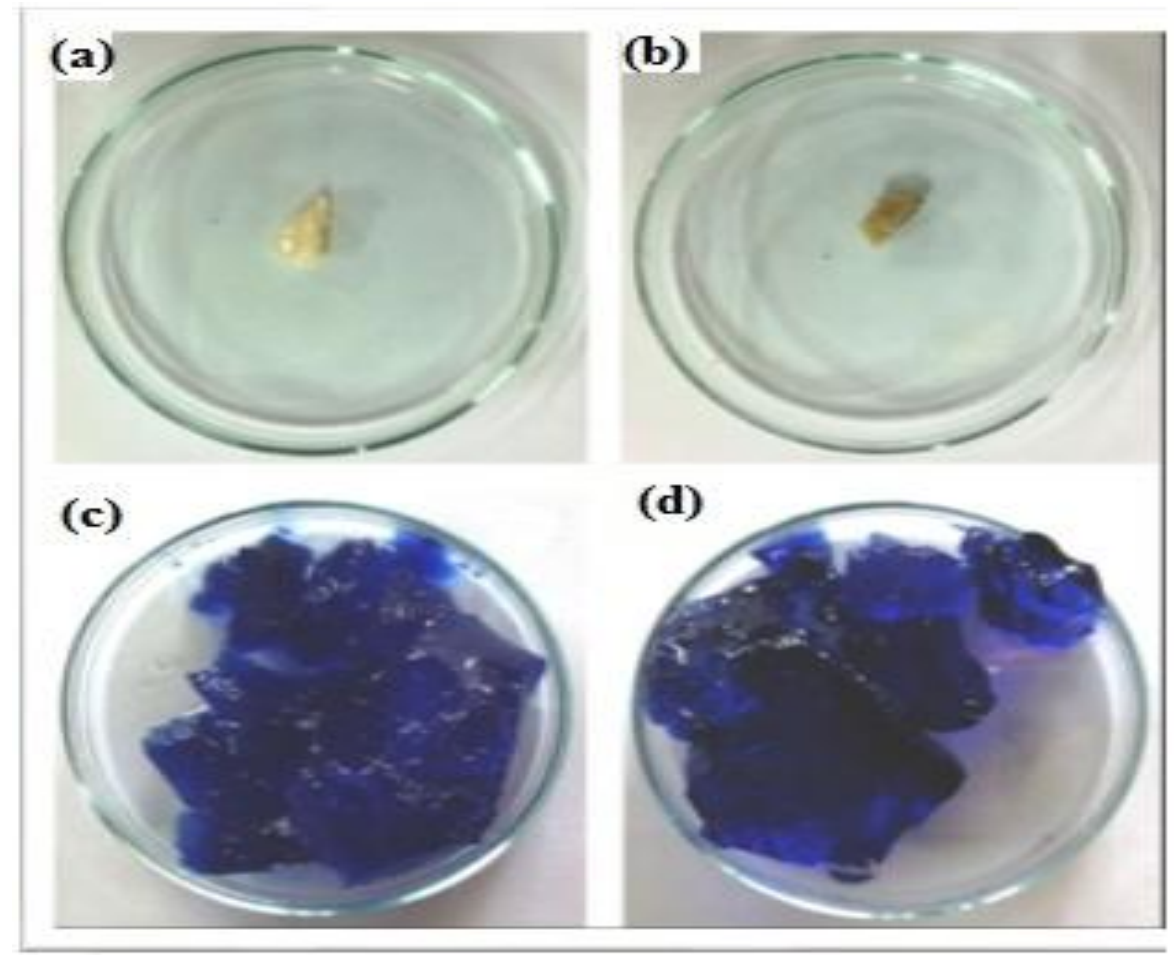

Figure 6. Images of sodium alginate-g-poly(acrylic acid-co-acryl amide) hydrogel and sodium alginate-g-poly(acrylic acid-co-acryl amide)/clinoptilolite hydrogel nano-composite samples before (a, b) adsorption of methylene blue dye and after (c, d) adsorption of methylene blue dye solution (Rashidzadeh et al., 2015). Reprinted with permission from (Rashidzadeh et al., 2015). Copyright 2015 Springer. 

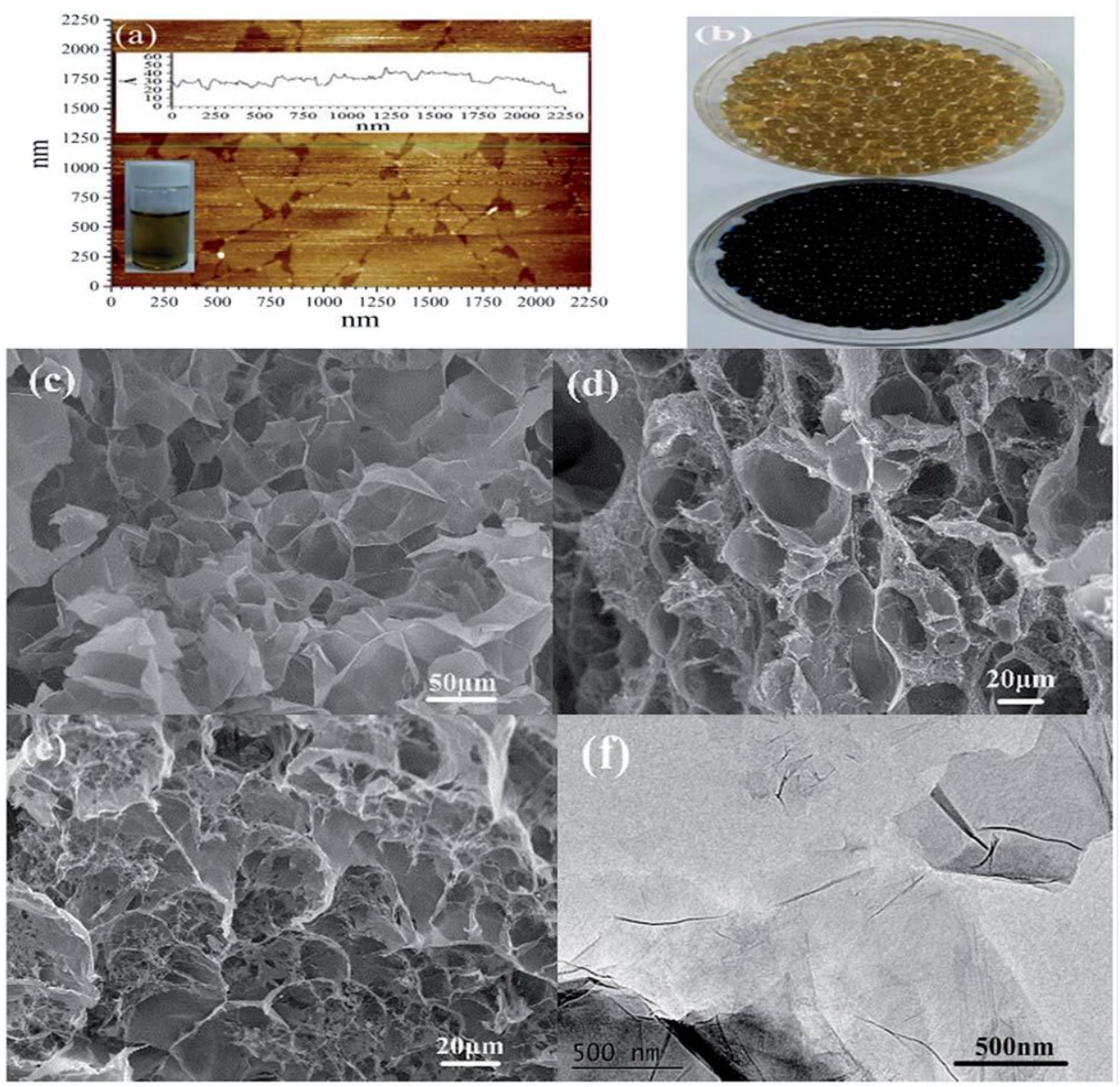

Figure 7. (a) Atomic force microscopy image of graphene oxide, (b) image of sodium alginate/ $\beta$-cyclodextrin/graphene oxide hydrogel nano-composite and methylene blue loaded sodium alginate/ß-cyclodextrin/graphene oxide hydrogel nano-composite, (c-e) SEM images of sodium alginate/ $\beta$-cyclodextrin/graphene oxide hydrogel nano-composite and (f) TEM image of graphene oxide (Wu et al., 2017). Reproduced from (Wu et al., 2017). Published by Royal Society of Chemistry. 

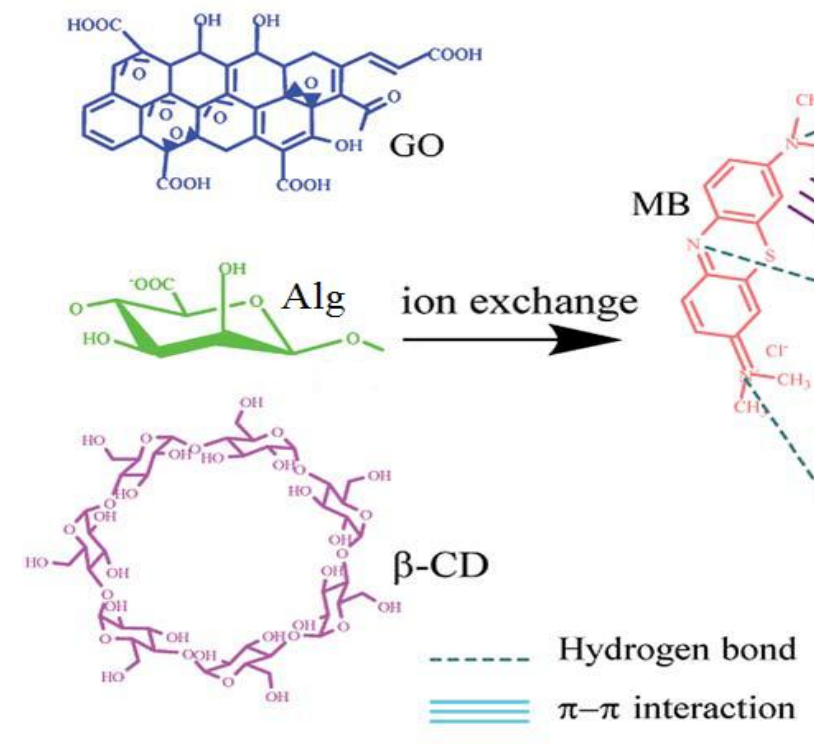

$\bar{\equiv}$ Electrostatic attraction cyclodextrin/graphene oxide hydrogel nano-composite (Wu et al., 2017). Reproduced from (Wu et al., 2017). Published by Royal Society of Chemistry. 
Figure 9. Possible mechanism for interaction of cationic methylene blue (MB) dye with titania incorporated sodium alginate cross-linked acrylic acid hydrogel nano-composite (Alg-cl-poly(AA)-TiO $)$ (Thakur et al., 2016). Reprinted with permission from (Thakur et al., 2016). Copyright 2016 Elsevier. 
Figure 10. (a-c) Photographs of pure polyacrylamide hydrogel under compression, (d-f) photographs of graphene oxide/sodium alginate/polyacrylamide hydrogel nano-composite under compression, (g) general representation for graphene oxide/sodium alginate/polyacrylamide ternary hydrogel nano-composite (Fan et al., 2013). Reprinted with permission from (Fan et al., 2013). Copyright 2013 Royal Society of Chemistry. 

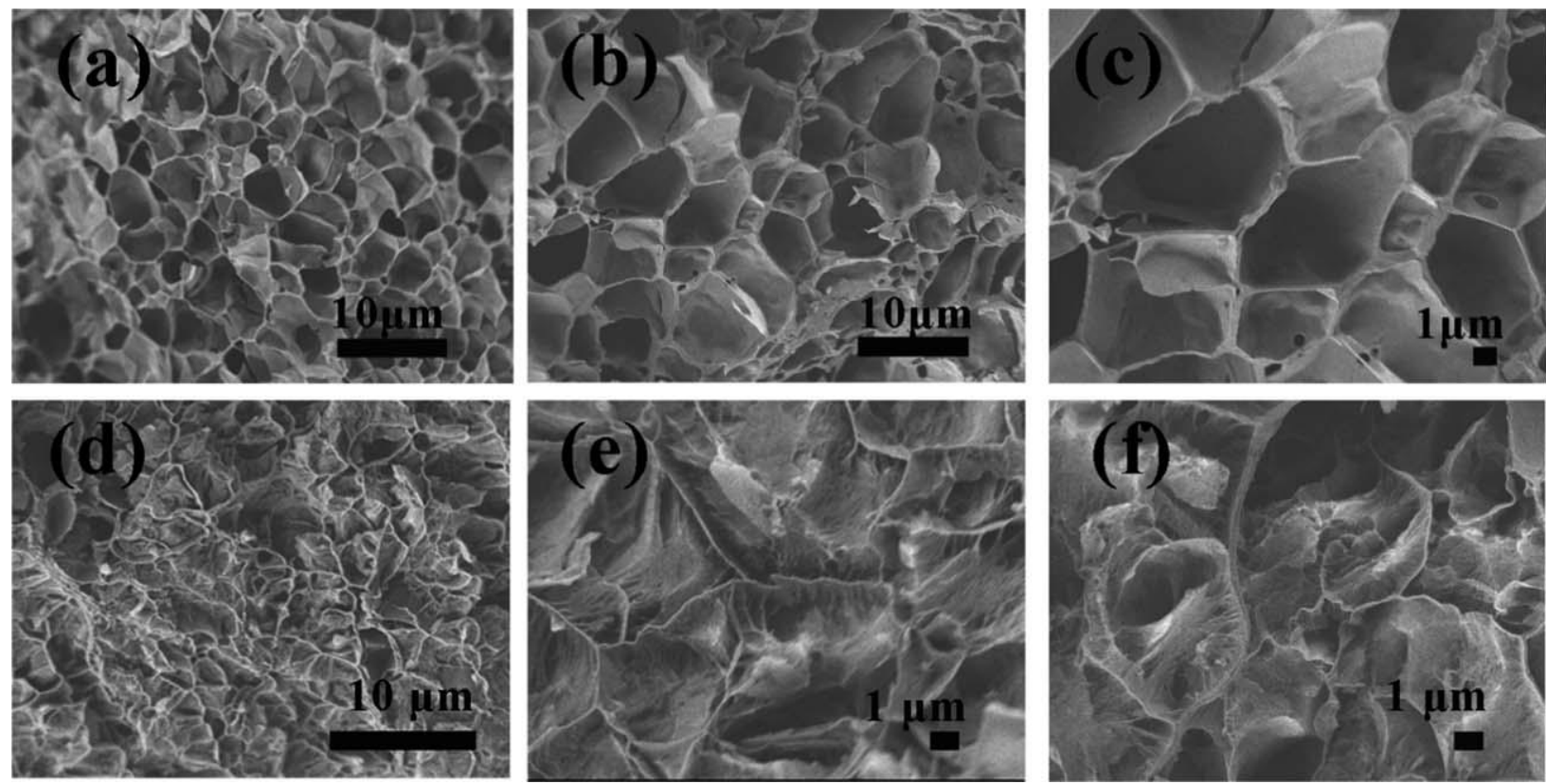

Figure 11. (a) SEM images of (a) pure polyacrylamide hydrogel, (b, c) sodium alginate/polyacrylamide hydrogel, (d-f) graphene oxide/sodium alginate/polyacrylamide ternary hydrogel nano-composite (Fan et al., 2013). Reprinted with permission from (Fan et al., 2013). Copyright 2013 Royal Society of Chemistry. 
Figure 12. Different dye solutions before and after the adsorption by graphene oxide/sodium alginate/polyacrylamide ternary hydrogel nano-composite. brilliant green (BG), methylene blue (MB), malachite green (MG), rhodamine 6G (R6G), methyl orange (MO), bordeaux red (BR), calcein (CA) and rose bengal sodium salt (RB) (Fan et al., 2013).Reprinted with permission from (Fan et al., 2013). Copyright 2013 Royal Society of Chemistry. 


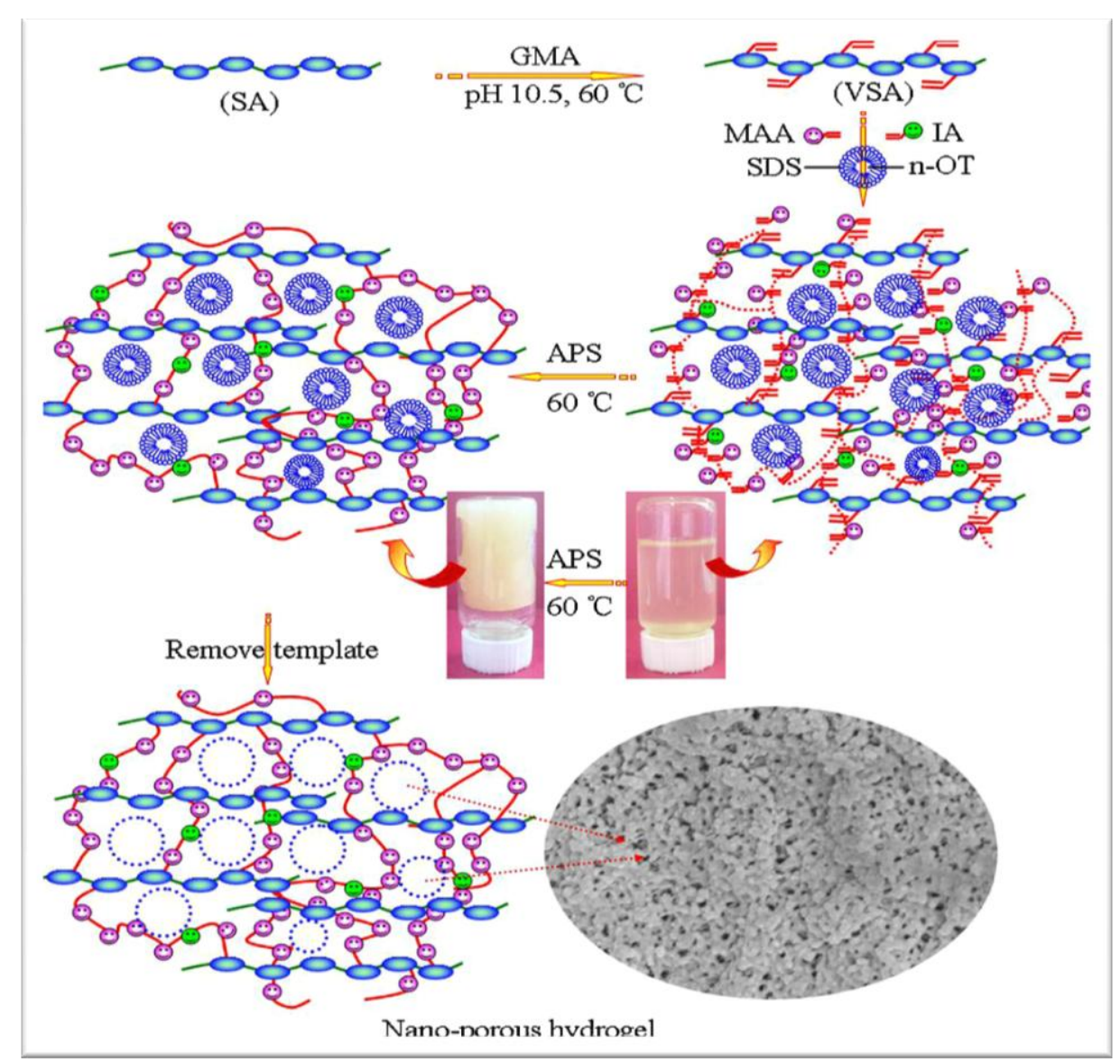

Figure 13. Potential mechanism for the formation of nano-porous vinyl-functionalized sodium alginate-co-methyl acrylic acid-co-italic acid hydrogel (Wang et al., 2013b). Reprinted with permission from (Wang et al., 2013b). Copyright 2013 Elsevier. 


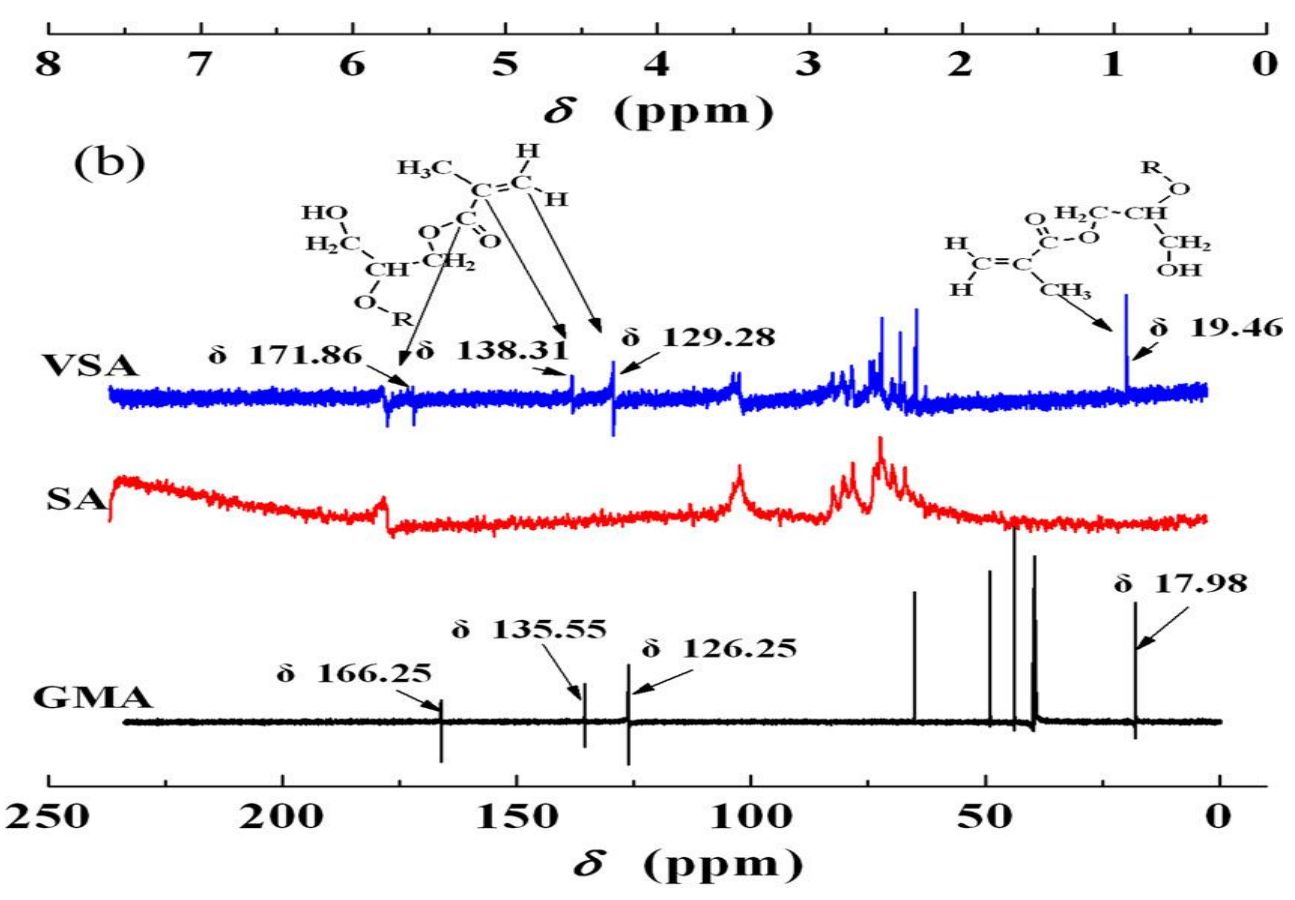

Figure 14. (a) ${ }^{1} \mathrm{H}$ NMR spectra of glycidyl methacrylate, sodium alginate and vinylfunctionalized sodium alginate, (b) ${ }^{13} \mathrm{C}$ NMR spectra of glycidyl methacrylate, sodium alginate and vinyl-functionalized sodium alginate (Wang et al., 2013b). Reprinted with permission from (Wang et al., 2013b). Copyright 2013 Elsevier. 


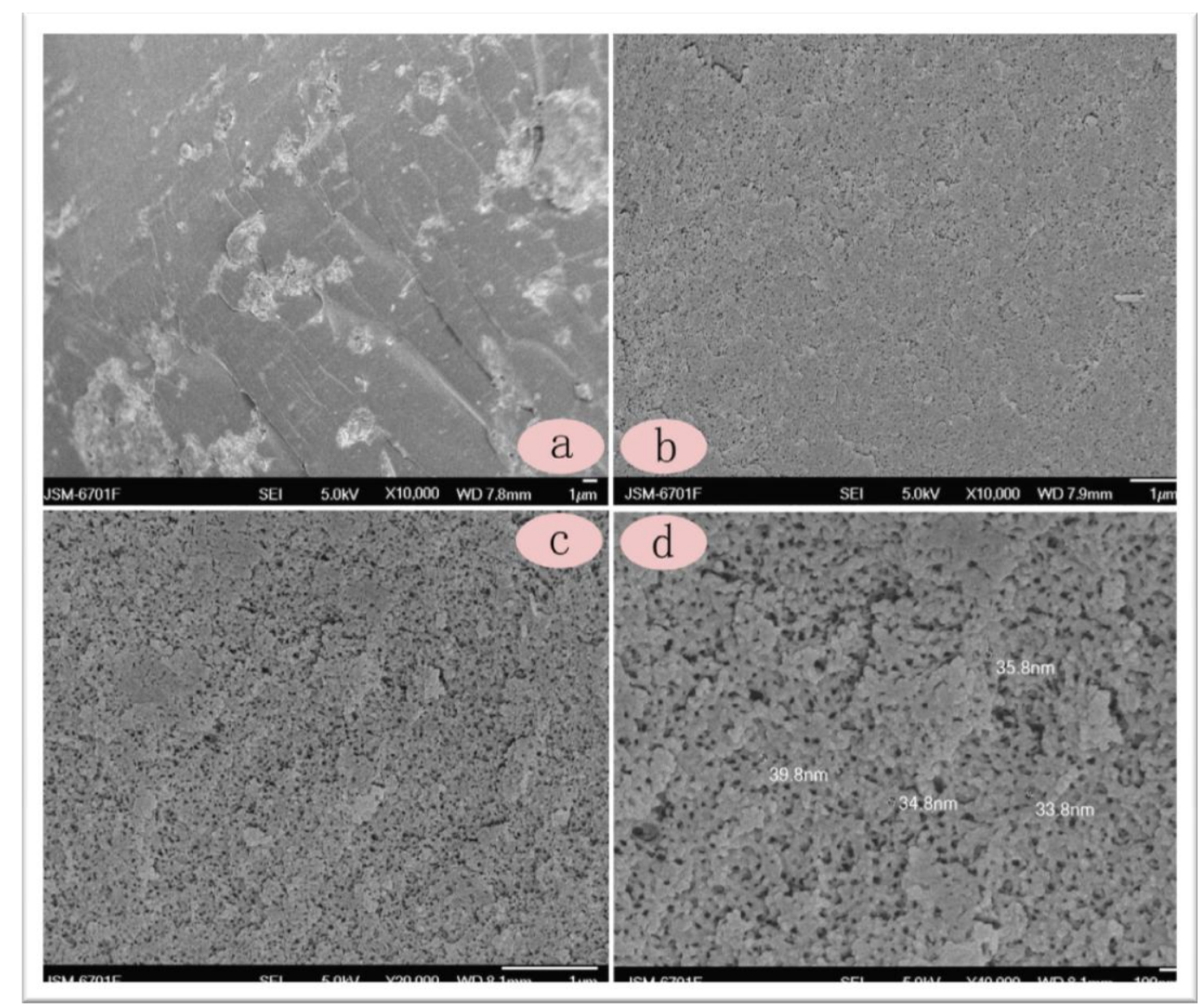

Figure 15. FESEM images of (a) non porous vinyl-functionalized sodium alginate-comethyl acrylic acid-co-italic acid hydrogel, (b-d) nano-porous vinyl-functionalized sodium alginate-co-methyl acrylic acid-co-italic acid hydrogel at different magnification (Wang et al., 2013b). Reprinted with permission from (Wang et al., 2013b). Copyright 2013 Elsevier. 
Figure 16. Proposed scheme for the synthesis of sodium alginate-g-polyacrylic acid/polyvinylpyrrolidone/gelatin granular hydrogel (Wang et al., 2013a). Reprinted with permission from (Wang et al., 2013a). Copyright 2013 Springer. 


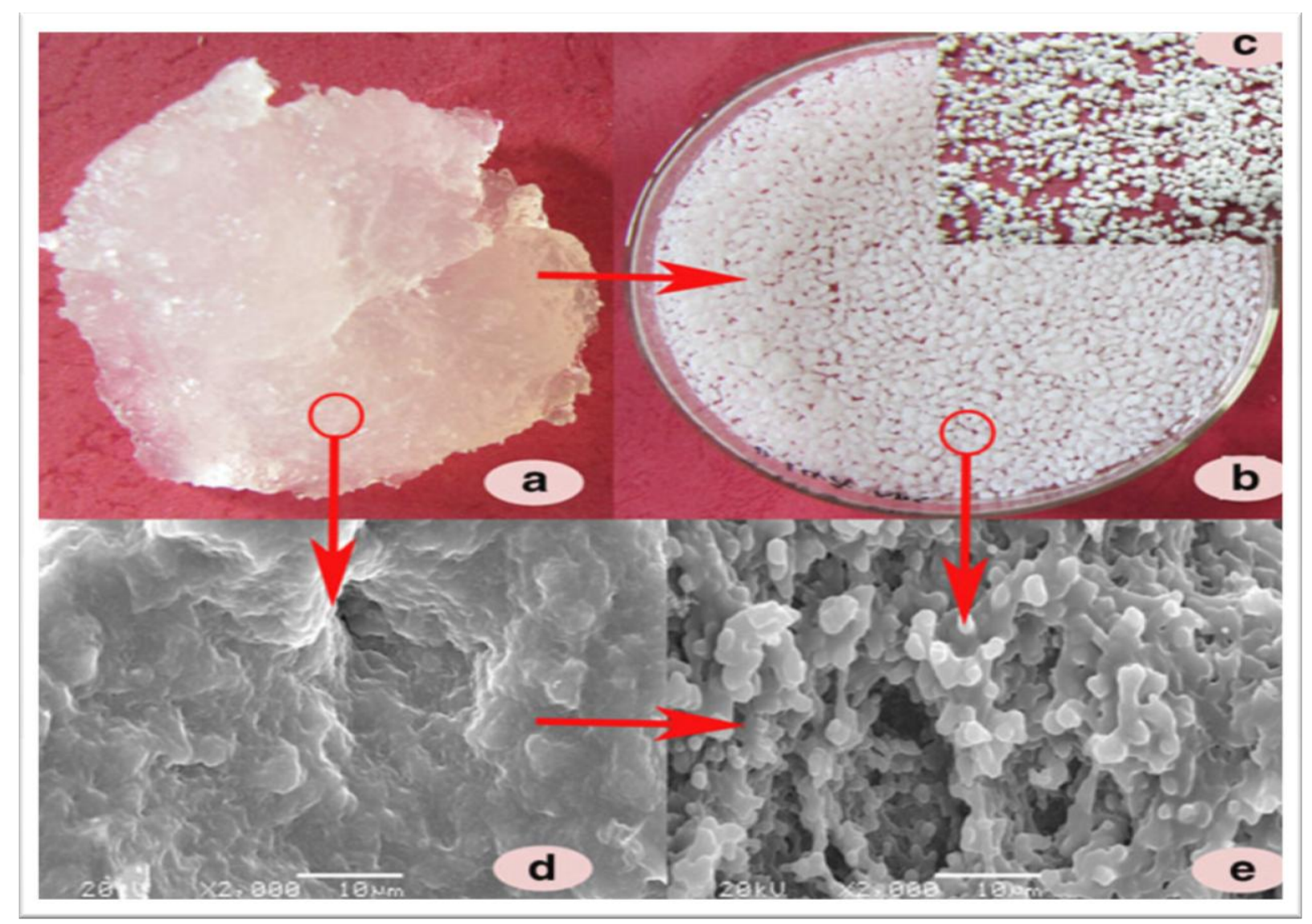

Figure 17. Digital images of (a) sodium alginate-g-polyacrylic acid hydrogel, (b) sodium alginate-g-polyacrylic acid/polyvinylpyrrolidone/gelatin granular hydrogel, (c) sodium alginate-g-polyacrylic acid/polyvinylpyrrolidone/gelatin granular hydrogel in dry state. SEM images of (d) sodium alginate-g-polyacrylic acid hydrogel, (e) sodium alginate-gpolyacrylic acid/polyvinylpyrrolidone/gelatin granular hydrogel (Wang et al., 2013a). Reprinted with permission from (Wang et al., 2013a). Copyright 2013 Springer. 


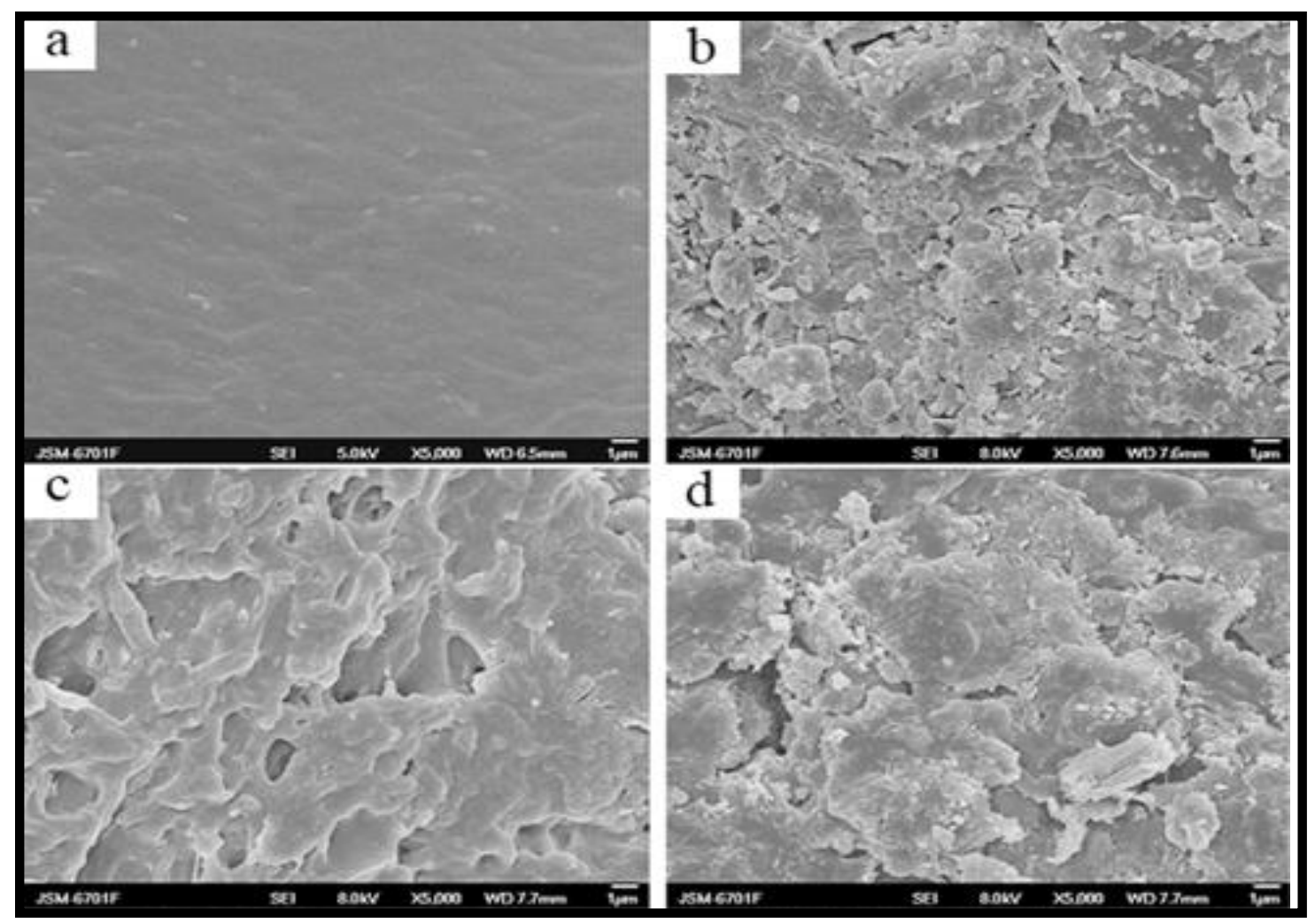

Figure 18. FESEM images of (a) sodium alginate-g-sodium acrylatehydrogel, (b) medical stone (c) sodium alginate-g-sodium acrylate/medical stone hydrogel composite with $0.93 \mathrm{~g}$ medical stone, (d) sodium alginate-g-sodium acrylate/medical stone hydrogel composite with 3.57 g medical stone (Gao et al., 2011). Reprinted with permission from (Gao et al., 2011). Copyright 2011 Springer. 
Figure 19. Formation of (a) reduced graphene (RGO) hydrogel, (b) beads of alginate hydrogel, (c) hydrogel bead of graphene/alginate composite (Zhuang et al., 2016). Reproduced from (Zhuang et al., 2016). Published by Royal Society of Chemistry. 

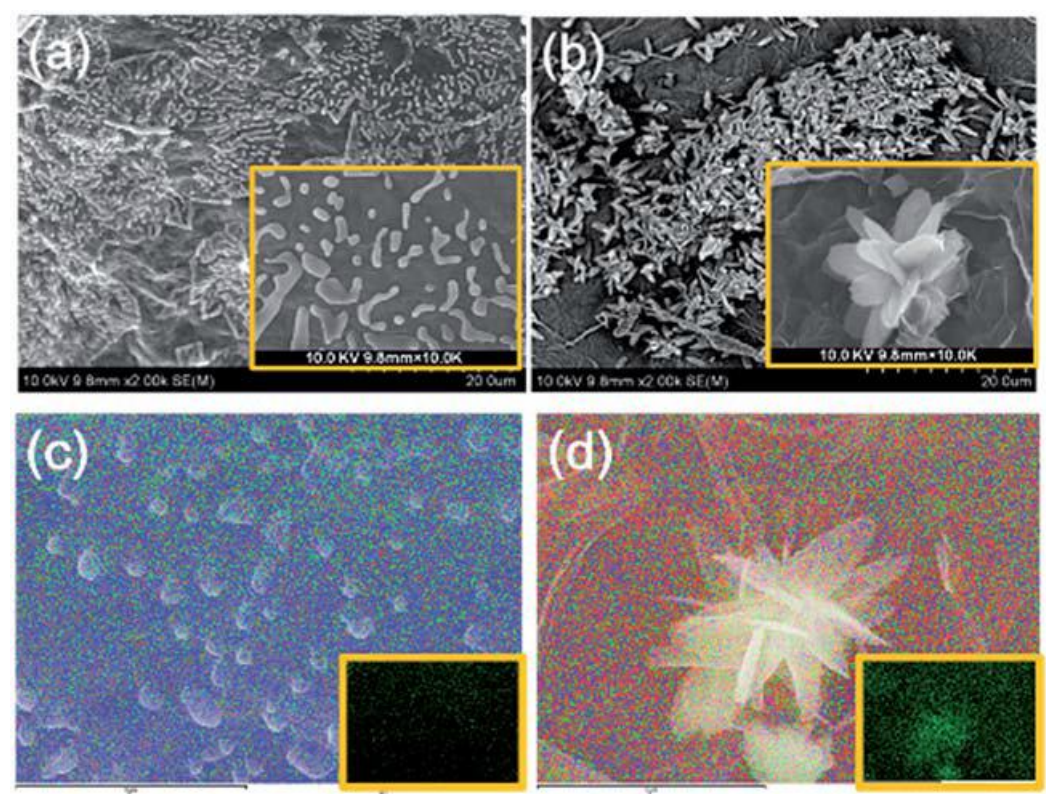

Figure 20. SEM micrograph of (a) graphene/alginate single network and (b) graphene/alginate double network, elemental mapping of (c) graphene/alginate single network, (d) graphene/alginate double network, with insets of mapping of oxygen element (Zhuang et al., 2016). Reproduced from (Zhuang et al., 2016). Published by Royal Society of Chemistry. 


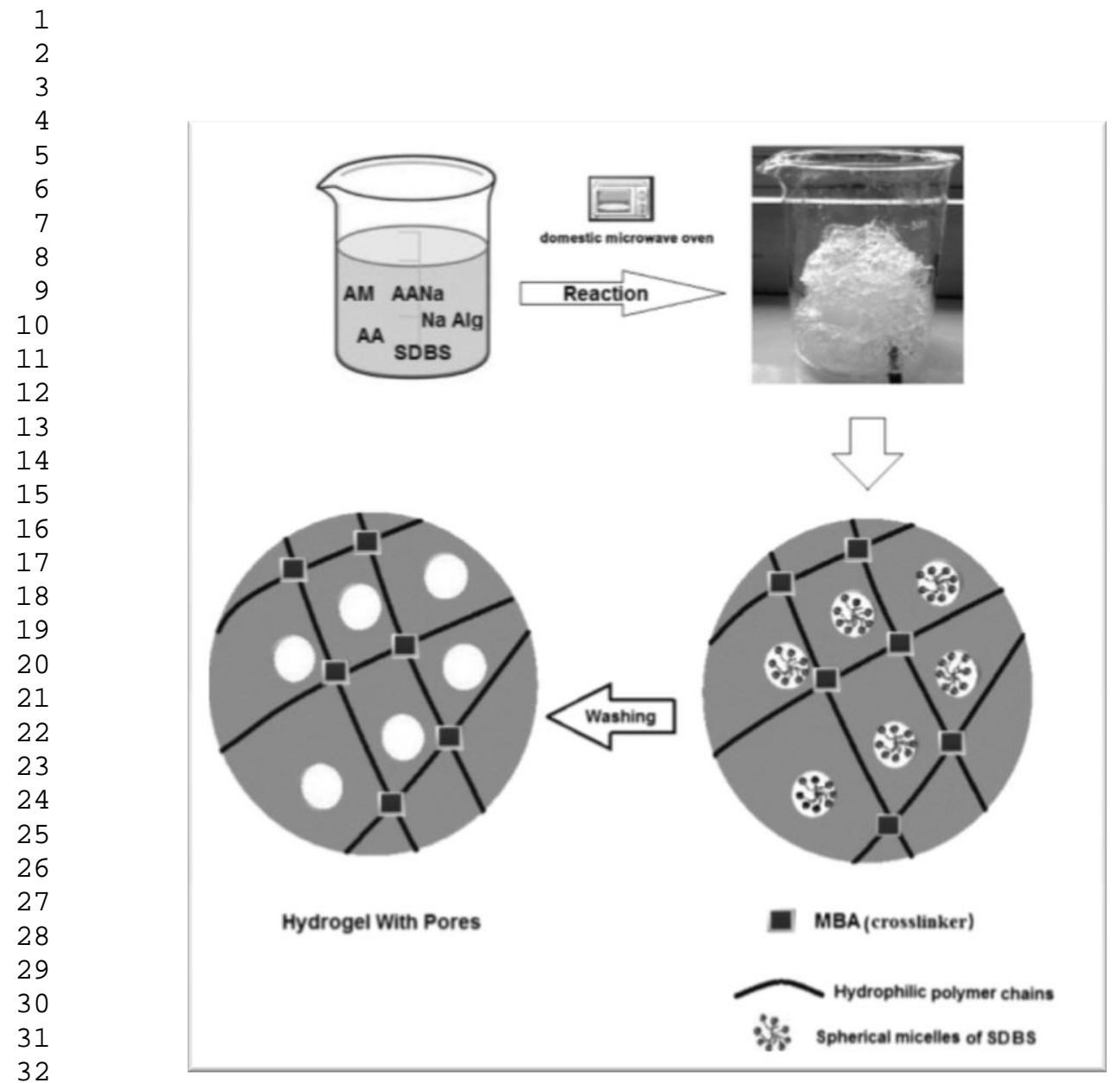

Figure 21. Schematic presentation for the synthesis of sodium alginate-g-poly(acrylic acidco-acrylamide)hydrogel (Tally and Atassi, 2016). Reprinted with permission from (Tally and Atassi, 2016). Copyright 2016 Springer. 
Figure 22. XRD spectra of (a) sodium alginate, (b) poly(acrylic acid-co-acrylamide), (c) sodium alginate-g-poly(acrylic acid-co-acrylamide) hydrogel(Tally and Atassi, 2016). Reprinted with permission from (Tally and Atassi, 2016). Copyright 2016 Springer. 

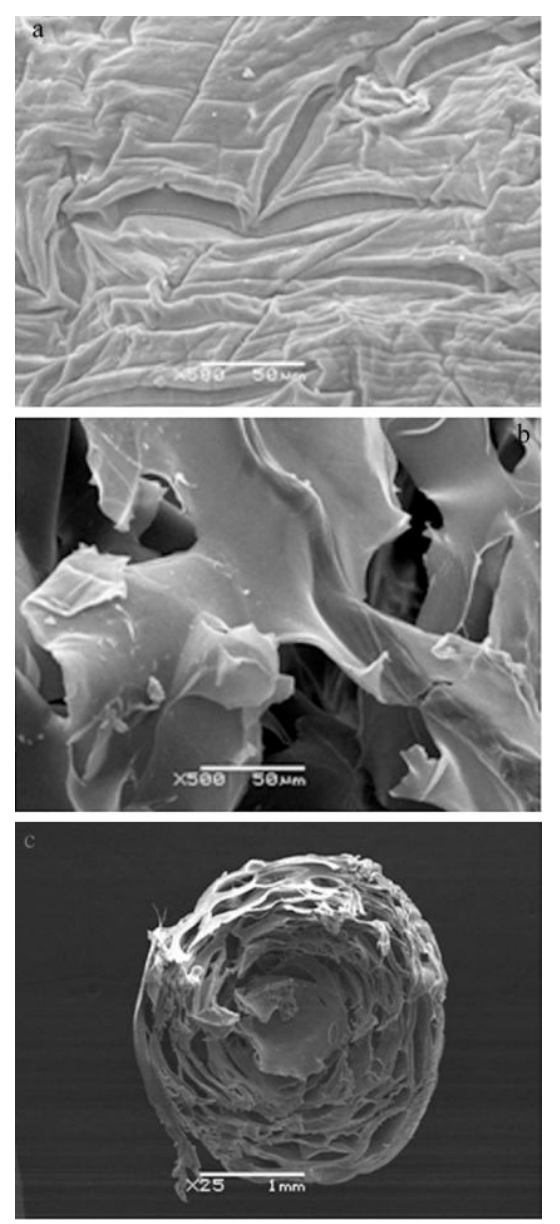

Figure 23. SEM images of (a) pure sodium alginate gel bead, (b) sodium alginatecarboxymethyl cellulose gel bead, (c) cross section of sodium alginate-carboxymethyl cellulose gel bead (Ren et al., 2016). Reprinted with permission from (Ren et al., 2016). Copyright 2016 Elsevier. 
Table 1. Sodium alginate based hydrogels for removal of organic pollutants.

\begin{tabular}{|c|c|c|c|}
\hline Sr. No. & Hydrogel Composites & $\begin{array}{l}\text { Organic } \\
\text { Pollutants }\end{array}$ & References \\
\hline 1. & $\begin{array}{l}\text { Sodium alginate-poly(acrylic acid) } \\
\text { superabsorbent hydrogel }\end{array}$ & $\begin{array}{l}\text { Victoria blue } \mathrm{R} \text { and } \\
\text { Rhodamine } 6 \mathrm{G}\end{array}$ & $\begin{array}{l}\text { (Thakur and } \\
\text { Arotiba, n.d.) }\end{array}$ \\
\hline 2. & $\begin{array}{l}\text { Sodium alginate and silicone dioxide based } \\
\text { organic/inorganic nano-composite hydrogel }\end{array}$ & Methylene blue & $\begin{array}{l}\text { (Hosseinzadeh and } \\
\text { Abdi, 2017) }\end{array}$ \\
\hline 3. & $\begin{array}{l}\text { Sodium alginate based titanium dioxide } \\
\text { hydrogel beads }\end{array}$ & Cationic dyes & (Lam et al., 2017) \\
\hline 4. & $\begin{array}{l}\text { Sodium alginate based } \beta \text {-cyclodextrin/ } \\
\text { graphene oxide nano-composite hydrogel }\end{array}$ & Methylene blue & (Wu et al., 2017) \\
\hline 5. & $\begin{array}{l}\text { Sodium alginate based } \mathrm{TiO}_{2} \text { nano-composite } \\
\text { hydrogel }\end{array}$ & Methyl violet & $\begin{array}{l}\text { (Thakur and } \\
\text { Arotiba, 2017) }\end{array}$ \\
\hline 6. & $\begin{array}{l}\text { Sodium alginate/ polyacrylic acid/ } \mathrm{TiO}_{2} \\
\text { nano-composite hydrogel }\end{array}$ & Methylene blue & $\begin{array}{l}\text { (Thakur et al., } \\
\text { 2016) }\end{array}$ \\
\hline 7. & $\begin{array}{l}\text { Sodium alginate based silver nano- } \\
\text { composite hydrogel }\end{array}$ & $\begin{array}{l}\text { Methylene } \\
\text { blue }\end{array}$ & $\begin{array}{l}\text { (Karthiga Devi et } \\
\text { al., 2016) }\end{array}$ \\
\hline 8. & $\begin{array}{l}\text { Sodium alginate-g-poly (acrylic acid-co- } \\
\text { acryl amide)/clinoptilolite nano-composite } \\
\text { hydrogel }\end{array}$ & $\begin{array}{l}\text { Methylene } \\
\text { blue }\end{array}$ & $\begin{array}{l}\text { (Rashidzadeh et } \\
\text { al., 2015) }\end{array}$ \\
\hline 9. & $\begin{array}{l}\text { Sodium alginate based kappa-carrageenan/ } \\
\text { sodium montmorillonite nano-composite } \\
\text { hydrogel }\end{array}$ & Crystal violet & $\begin{array}{l}\text { (Mahdavinia et al., } \\
\text { 2013) }\end{array}$ \\
\hline 10. & $\begin{array}{l}\text { Sodium alginate based graphene oxide/ } \\
\text { polyacrylamide nano-composite hydrogel }\end{array}$ & $\begin{array}{l}\text { Cationic and } \\
\text { anionic dyes }\end{array}$ & (Fan et al., 2013) \\
\hline 11. & $\begin{array}{l}\text { Sodium alginate based semi-IPN/ acrylic } \\
\text { copolymer nano-composite hydrogel }\end{array}$ & Methyl violet & $\begin{array}{l}\text { (Bhattacharyya and } \\
\text { Ray, 2015) }\end{array}$ \\
\hline 12. & $\begin{array}{l}\text { Sodium alginate based organo-bentonite } \\
\text { nano-composite hydrogel }\end{array}$ & $\begin{array}{l}\text { Methylene blue and } \\
\text { Methyl orange }\end{array}$ & $\begin{array}{l}\text { (Belhouchat et al., } \\
\text { 2017) }\end{array}$ \\
\hline
\end{tabular}


Table 2. Sodium alginate based hydrogels for removal of inorganic pollutants.

\begin{tabular}{|c|c|c|c|}
\hline Sr. No. & Hydrogel Composites & $\begin{array}{l}\text { Inorganic } \\
\text { Pollutant }\end{array}$ & References \\
\hline 1. & $\begin{array}{l}\text { Sodium alginate based carboxymethyl } \\
\text { cellulose hydrogel beads }\end{array}$ & $\mathrm{Pb}(\mathrm{II})$ & $\begin{array}{l}\text { (Ren et al., } \\
\text { 2016) }\end{array}$ \\
\hline 2. & $\begin{array}{l}\text { Sodium alginate-g-poly (acrylic acid-co- } \\
\text { acrylamide) nano-composite hydrogel }\end{array}$ & $\begin{array}{l}\mathrm{Pb}(\mathrm{II}), \mathrm{Cd}(\mathrm{II}) \\
\mathrm{Ni}(\mathrm{II}) \text { and } \mathrm{Cu}(\mathrm{II})\end{array}$ & $\begin{array}{l}\text { (Tally and } \\
\text { Atassi, 2016) }\end{array}$ \\
\hline 3. & $\begin{array}{l}\text { Alginate/reduced graphene double-network } \\
\text { hydrogel beads and Alginate/reduced } \\
\text { graphene single-network hydrogel beads }\end{array}$ & $\mathrm{Cu}(\mathrm{II})$ and $\mathrm{Cr}_{2} \mathrm{O}_{7}^{2-}$ & $\begin{array}{l}\text { (Zhuang et al., } \\
\text { 2016) }\end{array}$ \\
\hline 4. & $\begin{array}{l}\text { Vinyl-functionalized sodium alginate-co- } \\
\text { methyl acrylic acid-co-italic acid nano- } \\
\text { composite hydrogel }\end{array}$ & $\mathrm{Pb}(\mathrm{II})$ & $\begin{array}{l}\text { (Wang et al., } \\
\text { 2013b) }\end{array}$ \\
\hline 5. & $\begin{array}{l}\text { Sodium alginate based granular nano- } \\
\text { composite hydrogel }\end{array}$ & $\begin{array}{l}\mathrm{Ni}(\mathrm{II}), \mathrm{Cu}(\mathrm{II}) \\
\mathrm{Zn}(\mathrm{II}) \text { and } \mathrm{Cd}(\mathrm{II})\end{array}$ & $\begin{array}{l}\text { (Wang et al., } \\
\text { 2013a) }\end{array}$ \\
\hline 6. & $\begin{array}{l}\text { Sodium alginate-g-poly (sodium acrylate)/ } \\
\text { medical stone nano-composite hydrogel }\end{array}$ & $\begin{array}{l}\mathrm{Ni}(\mathrm{II}), \mathrm{Cu}(\mathrm{II}) \\
\mathrm{Zn}(\mathrm{II}) \text { and } \mathrm{Cd}(\mathrm{II})\end{array}$ & $\begin{array}{l}\text { (Gao et al., } \\
\text { 2011) }\end{array}$ \\
\hline 7. & $\begin{array}{l}\text { Tetra sodium thiacalix [4] } \\
\text { arenetetrasulfonate-sorption-sodium alginate } \\
\text { nano-composite hydrogel }\end{array}$ & $\begin{array}{l}\mathrm{Ni}(\mathrm{II}), \mathrm{Cu}(\mathrm{II}) \\
\mathrm{Pb}(\mathrm{II}), \mathrm{Cd}(\mathrm{II}) \\
\mathrm{Co}(\mathrm{II}) \text { and } \mathrm{Cr}(\mathrm{III})\end{array}$ & $\begin{array}{l}\text { (Lakouraj et al., } \\
\text { 2014) }\end{array}$ \\
\hline 8. & $\begin{array}{l}\text { Sodium alginate hydrogel beads by post } \\
\text { cross-linking }\end{array}$ & $\begin{array}{l}\mathrm{Ag}(\mathrm{I}), \mathrm{Cu}(\mathrm{II}) \text { and } \\
\mathrm{Fe}(\mathrm{III})\end{array}$ & (Lu et al., 2015) \\
\hline 9. & Sodium alginate based membrane - filtration & $\mathrm{Ca}(\mathrm{II})$ and $\mathrm{Mg}(\mathrm{II})$ & $\begin{array}{l}\text { (Fatin-Rouge et } \\
\text { al., 2006) }\end{array}$ \\
\hline 10. & $\begin{array}{l}\text { Chitosan-alginate hydrogel beads and } \\
\text { chitosan-glycolic acid hydrogel beads }\end{array}$ & $\mathrm{Cu}(\mathrm{II})$ & $\begin{array}{l}\text { (Ngah and } \\
\text { Fatinathan, } \\
\text { 2008) }\end{array}$ \\
\hline
\end{tabular}




\title{
Recent progress in sodium alginate
} based sustainable hydrogels for environmental applications

\author{
Thakur, Sourbh
}

Elsevier

Thakur S, Sharma B, Verma A, et al., (2018) Recent progress in sodium alginate based sustainable hydrogels for environmental applications. Journal of Cleaner Production, Volume 198, October 2018, pp. 143-159

https://doi.org/10.1016/j.jclepro.2018.06.259

Downloaded from Cranfield Library Services E-Repository 